\title{
The Dramatic Play Al-Hurr Arriyahi: An Alliterative, Artistic, Analytical Reading
}

\author{
Mustafa Sajid Mustafa \\ Department of Arabic Language, Al-Maarif University College, Iraq \\ dr.mustafaalrawi@uoa.edu.iq
}

KEYWORDS: $\quad$ Dramatic Play, Macbeth, Theatrical Structure, Drama, Purification.

Crossref doi https://doi.org/10.51345/.v33i1.472.g259

\begin{abstract}
:
In an attempt to discover the poetic, theatrical, and dramatic aspects of al-Hur Arriyahi by AbdulRazzaq Abdul-Wahid, the researcher endeavors to explore the genre of this literary work in addition to explaining how the poetic and theatrical structures can harmonize. The researcher also inquires whether this work is appropriate for the stage or, like the rest of literary genres; it is just authored for reading. The researcher surveys the infrastructure of each of those genres which synergize to create this piece of art without mentioning the wonderful comparison made by Dr. Abdul-Wahid Lu'lu'a who judged it against (Macbeth) by Shakespeare since that study comprises all meeting and contrast points between the two literary works. Thus the researcher cannot add a valuable observation on the technical characteristics as well as the artistic values that have been comprised by ( $\mathrm{Lu}^{\prime} \mathrm{lu}$ 'a). I may have been extensive in some important joints due to their deep-seated valued contents. Hence I anticipate that it is appropriate and necessary to expand further in dissection as far as the research allows without drifting away from the basic target. The researcher, however, does not touch upon the (theatrical structure or characters) throughout the analysis process, because the former has witnessed important developments in literature worldwide, whereas the latter has accessed the setting of this literary work as complete creations. The researcher, on the other hand, does not favor unification of the terms such as (play, drama, poetry or artistic production) since the text amalgamate these titles (artistic genres) in an entangled, albeit, artistically harmonized and synergized way. Which creates a comprehensive, holistic and uninterrupted text?
\end{abstract}




\title{
المسرحية الدرامية الحر الرياحي: قراءة إجناسية، فنية، تحليلية
}

\author{
أ.د. مصطفى ساجد مصطفى

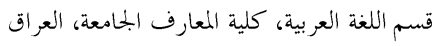 \\ dr.mustafaalrawi@uoa.edu.iq
}

المسرحية الدرامية، مكبث، الفيكل المسرحي، الدراما، التطهير.

الكلمات المفتاحية

Crossref doi) https://doi.org/10.51345/.v33i1.472.g259

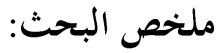

يحاول هذا البحث أن يتقصى ما يمكنه من كشف الجوانب الشعرية والمسرحية والدرامية، فضلاً عن البحث عن جنس هذا

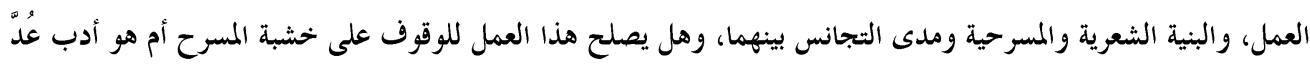

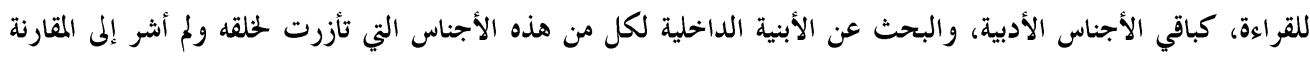
الرائعة - لدراسة الدكتور عبد الواحد لؤلؤة التي تقارن بين العمل و(مكبث) لأكفا استوفت ما بين العملين من وشائح اتصال

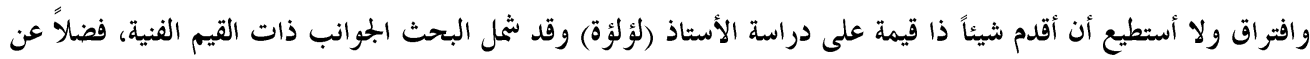
القيم المضمونة التي ينهض بها البحث، وربما أكون قد استرسلت في بعض المفاصل المهمة، لما لها من قيم فنية ومضمونيه عميقة الغور، رأيت من المناسب والضرورة أن أسرف في تشريكها على الوجه الذي يتحمله البحث ولا يشط بعيداً عن المدف الأساس

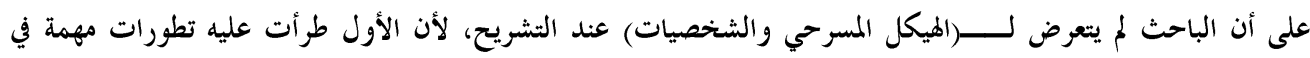
الآداب العالمية، أما الشخصيات فقد دخلت عالم العمل وهي مكتملة التكوين. ومن جانب آخر لم يؤثر الباحث توحيد المصطلح فمرة يقول (المسرحية أو الدراما أو القصيدة أو الأثر) لأن النص بكليته تتلاقح فيه هذه المسميات (الأنواع الفنية) على نحو

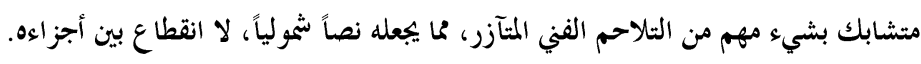

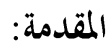

قبل الولوج الى متن هذا النص، لا بل من تحديل واضح لهويته الفنية، وإلى أي جنس من الأدب ينتمي. فهل (الحر الرياحي) مسرحية شعرية، كما شاع في بعض التعليقات والبحوث أم إذا قصيدة مسرحية؟ أم قصيدة محسرحة؟ وقبل الاجابة على هذا التساؤل يجدر بنا أن نحدد المصطلح على نهو واضح لا لبس

فالمسرحية سواء أكانت شعرية أم نثرية ها خصائصها واشتراطاها وابنيتها التي تميزها عن الأجناس الأخرى. فهي في جانب مهم منها تدخل جنس السرديات، لأكا تقص وتحكي الفعل. وهي على وفق 
هذا الوصف تدخل في خانة الدراما أكثر مما توصف بالغنائية، وهي عند ارسطو أرقى أنواع الشعر لما له من قدره على (التطهير)(1)، في حين يقف الشعر الغنائي في المتزلة الثالثة، في حين احتل الشعر الثرانية الغنائي مكان الصدارة عند العربي لأنه ((ديوان العرب خاصة والمنظوم من كلئ كلامها، والمقيد لأيامها، والشاهد

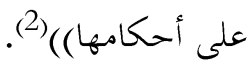
إن هذا التباين بين النظرتين يجعل من العمل الذي يجمعهما صعب المراس، إذي يمتاج لمن يتصدى له ثقافة

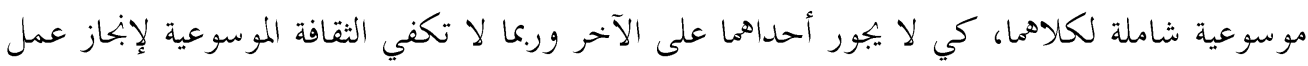

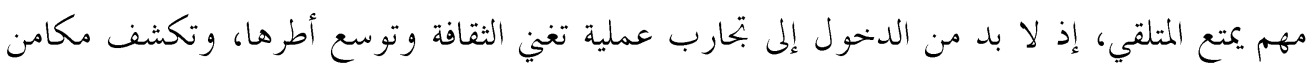

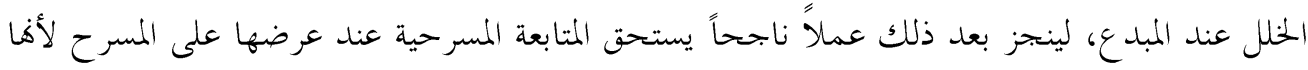
عمل جماعي تتآزر في انتاجه مواهب مختلفة تقوم أساساً على أفق ما يوفره النص المسرحي من بعن أبنية

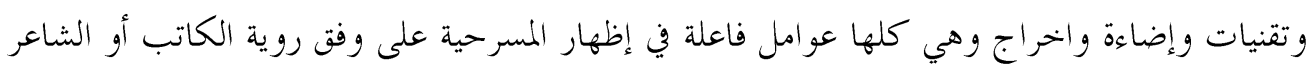

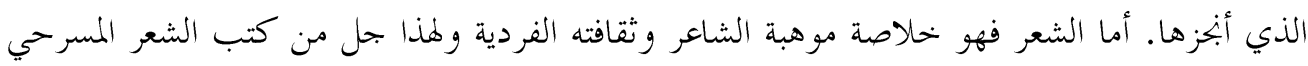
من المبدعين العرب وقعو اضحية هذا الانفصال البنيوي بين المسرح والشعر.

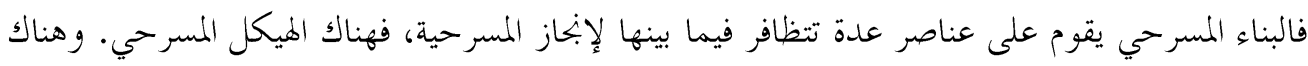

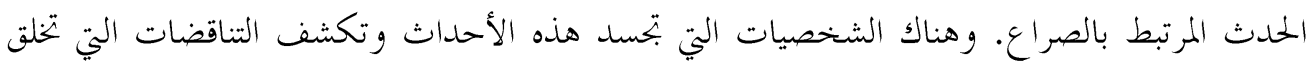

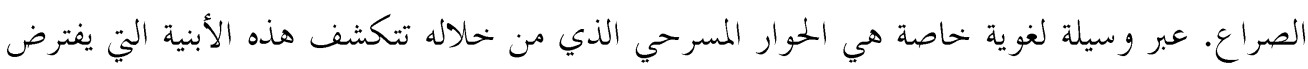
أن تكون متساوقة ومتوازنة، لكي تكون المسرحية قادرة على الإمساك بتلابيب المتلقي (الجمهور) .

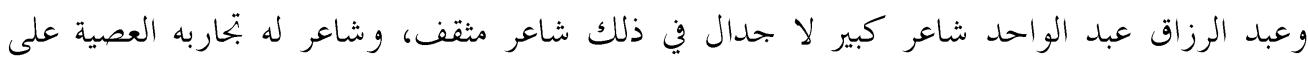

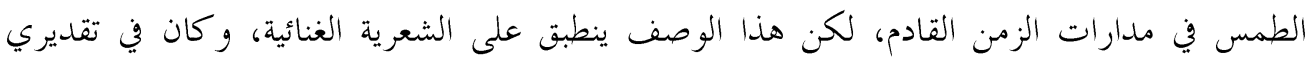

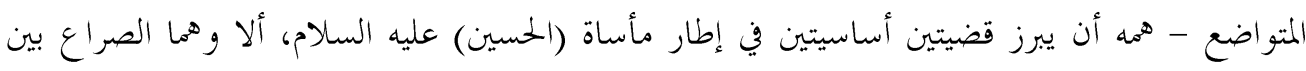

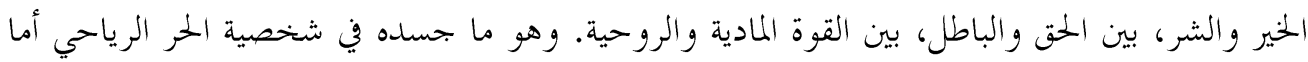

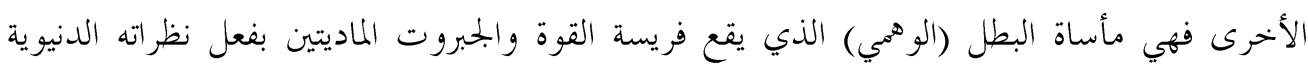

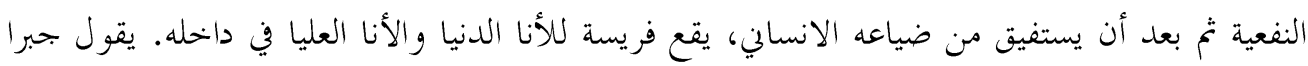

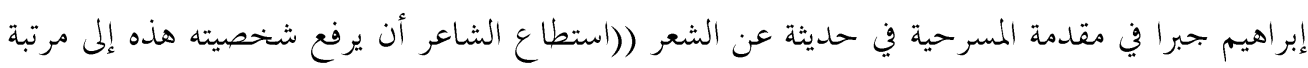
الشرير التراجيدي .... إنه ضرب من مكبث آخرر، لأن أقدامه على الجريمة الوحشية لا يخلو من طموح شخصي، وهو في الوقت نفسه لا يخلو من خيال يقظ يبقي على حسة برعب ما اقترف)(ج) (3). 
في هذه القصيدة المسرحية أو قل المسرحية الشعرية إن شأت - نلاحظ الصراع متأجحاً على نهو صاخب، لكنه صراع فكري ونفسي لا صراع وقائع وأحداث، فالأحداث تكاد تكون خامدة لأكا تأتي

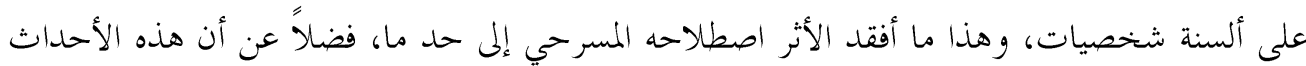

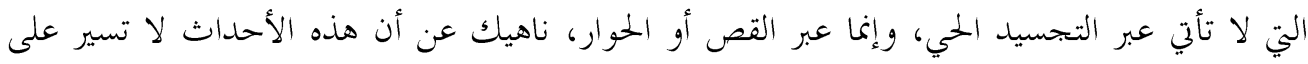

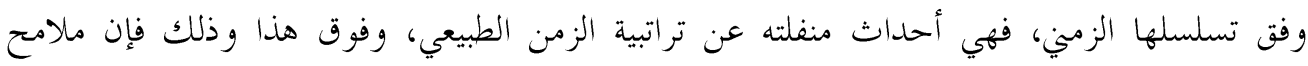

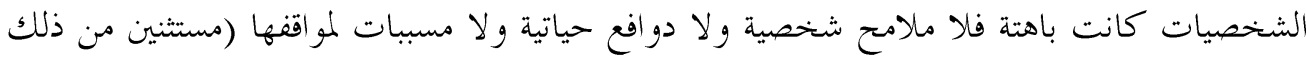

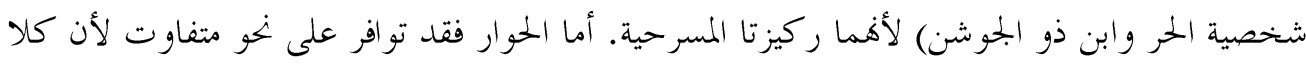

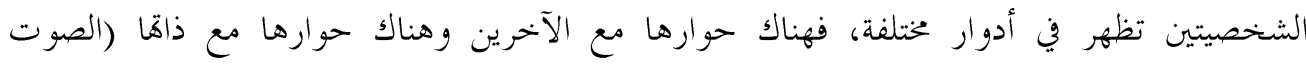
الداخلي) أو (المنلوج الداخلي) الذي أخذان مساحات شاسعة من جسد (متن) المسرحية، والمنلوج الداخلي يجب أن يكون على نطاق محدود في الأعمال المسرحية، ففي مسرحيات شكسبير نعثر على هذه اله

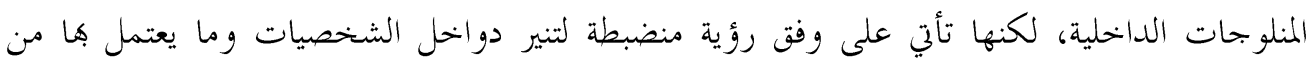
صراع داخلي. كل هذه الهنات حادث بنا إلى أن نطلق عليها (قصيدة ممسرحة) وليست مسرحية شعرية ويبقى هناك

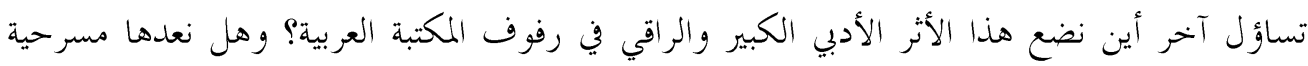

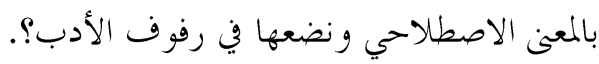

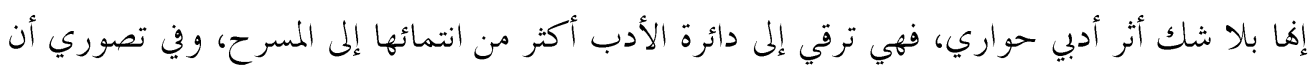

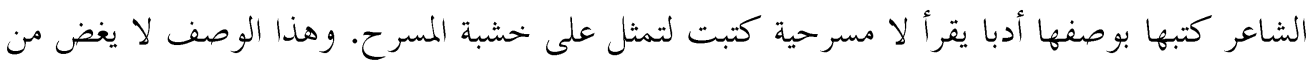
قيمتها الفنية أو الفكرية. فقد سبقتها الكثير من الآثار الأدبية الحوارية، وأصبح الحوار جنساً أدبياً معترفاً

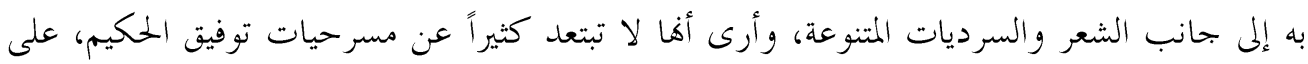

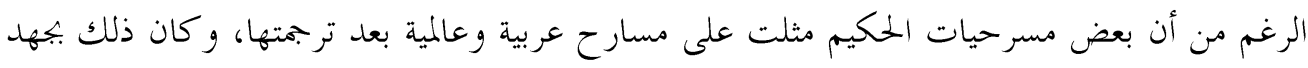
مظن من العاملين على بلورة النص المكتوب وتحو يله إلى مشاهد على الخشبة. يجدر بنا الآن بعد الإطلالة

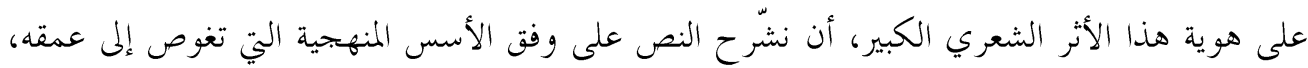

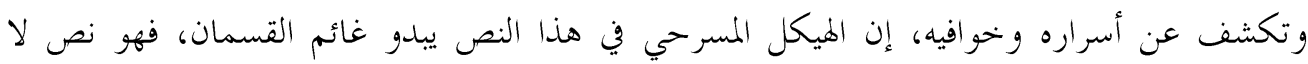

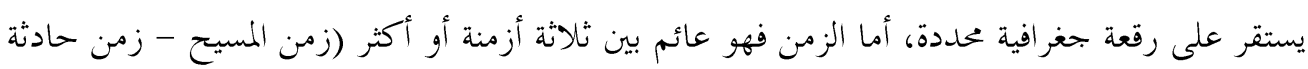

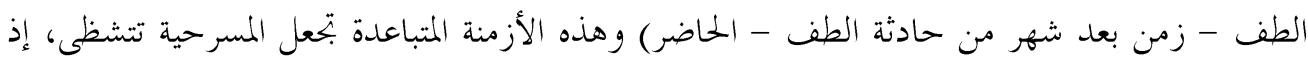
لا يمكن ربط أحداثها عبر مشهد مسرحي يجسد المأساة، ربما تصلح لمنتجة سينمائية لها القدرة على القفز 
بالزمن عبر مشاهد متو الية أو متباعدة على حسب رؤية فنية محكمة. لأن المقصود بالمسرح الشعري ((هو

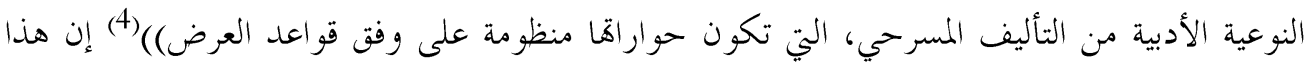

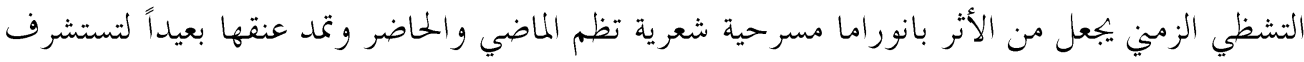

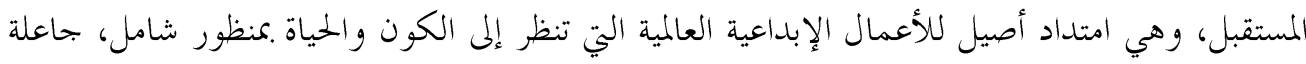
من الماضي رحما يحتضن الحاضر والمستقبل لذلك تنأى بذاتا عن التحديد و التأطير.

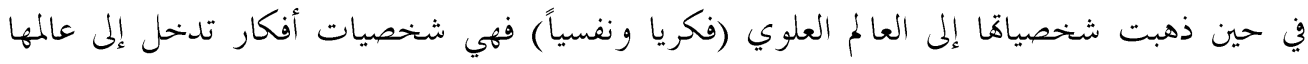
مكتملة الرؤى والأحاسيس، ومثل هذه الشخصيات برع بتشكيلها الروائي الانكليزي (الدوس هسكلي)

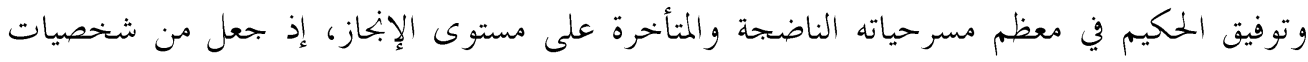

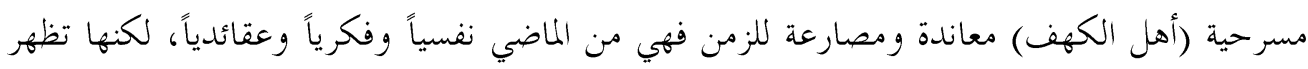
في غير ماضيها الزمني إذ تحاول أن تتساوق مع الحاضر، لكن سطوة الزمن وقانونه المتطور يقف أمامها بالمرصاد، فتقرر الانسحاب و العودة إلى الكهف. فاذا تفحصنا شخصية (الحر) في متن الأثر الأدبي وجداناه صاحب متزلة رفيعة في عشيرته ومترله حربية

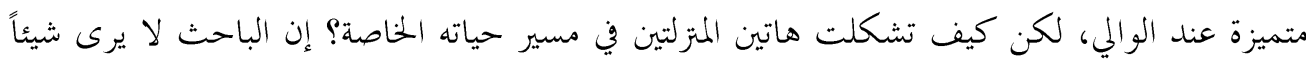

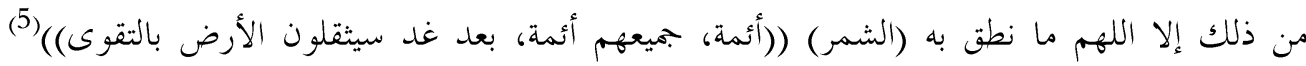

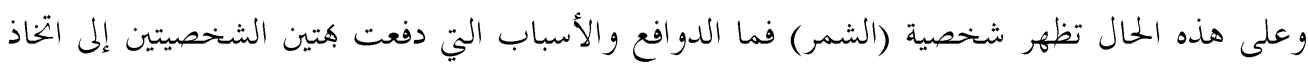
موقفهما - كل على حدة - من (الحسين) عليه السلام إن موقف الشمر من النقاء الإنساني واضحاً

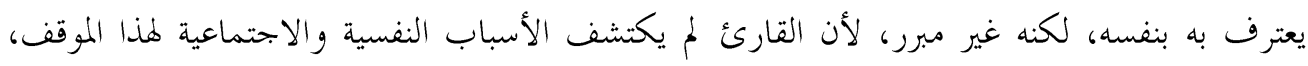

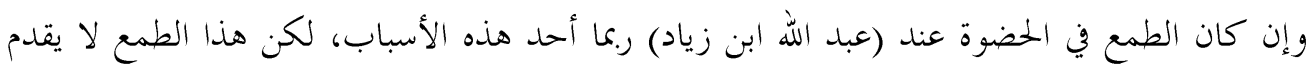
تفسيراً مقنعاً للمتلقي فمقتل الحسين علية السلام كافياً لاصطياده، لكن التمثيل وقطع الرأس يظهران

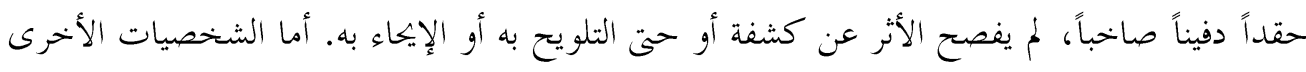

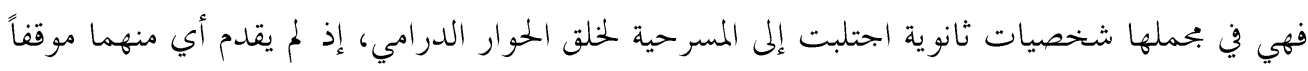

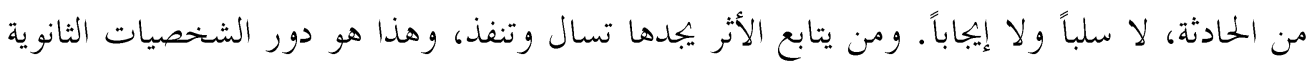

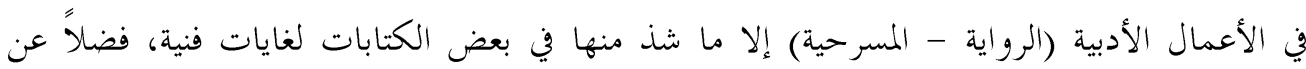

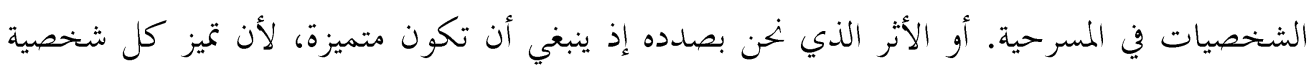

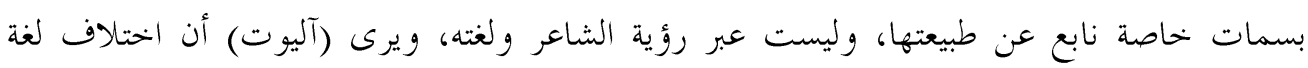

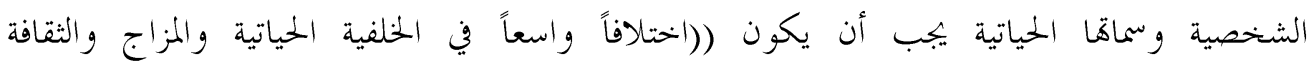


و الذكاء)(6) على أن هذا الأثر استطاع ببراعة أن يكشف عن ما يسمه الناقد علاقة ((التشابه

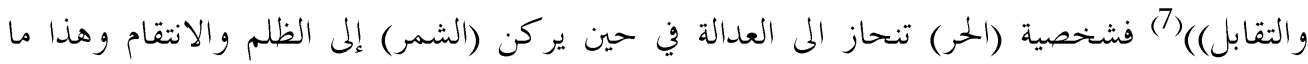
جعل المسرحية إلى حد بعيد، تمسك بالوجهين للكشف عن المفارقة، لأن المفارقة في مفهومها العام الثام تنمي الإحساس بالفجيعة، وتنحو بابتحاه النطهير الذي يبتغيه ارسطو في الشعر الدرامي (المسرحي).

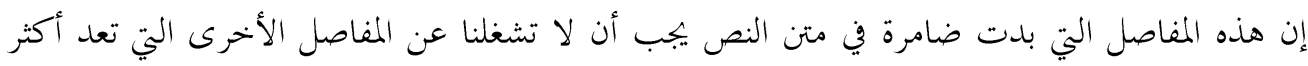
أهمية في المسرح وفي هذا (النص) بالذات.

\section{الصراع ودوره في تشكيل الأثر}

يتشكل الصراع عبر رؤيا فنية أرادها الشاعر لكي يكشف المفارقة الحادة بين موقفين، أحدهما قبل الفعل

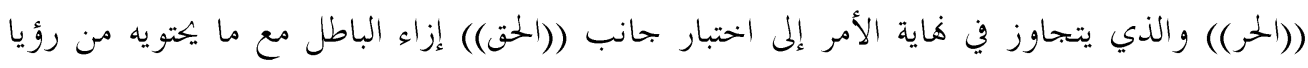

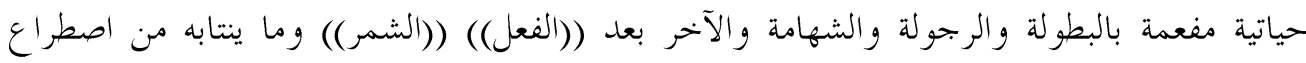
داخلي. فجر في داخله الخوف والهزيمة وانكسار الذات بانخيازه إلى الظلم والجريمة البشعة.

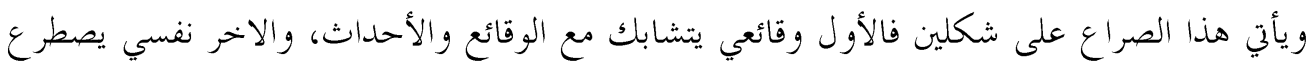

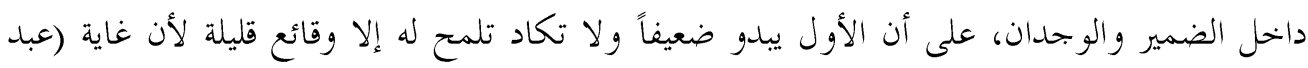
الو احد) تنصب على اللون الثاني الذي يرتقي بالعمل إلى مصاف (التراجيديا) الصادمة والمؤثرة.

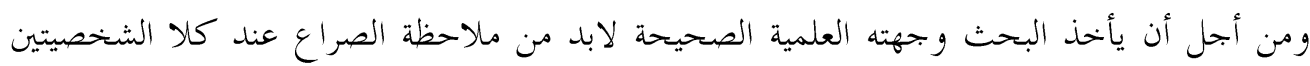

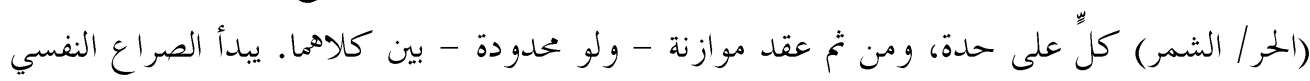
عند (الحر) لحظة البدء، حين يبدأ الهاجس بالحديث إلى الشخصية، إذها لحظة افتراق بين الموقف المعلن بئن والذات العميقة، والتي تفرز بعد حين القرار الأخير. الهاجس - إذا لخظة الصمت فلتختصر كلماتك انفسها تتر اجع؟ أم تقتل الآن؟

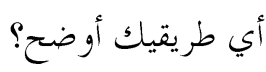
عقرب نضرب الليل بين ضلوعك مأكولة الظهر بعرب 
كان لسيفك رأي هو المدد

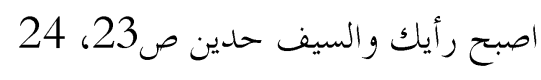

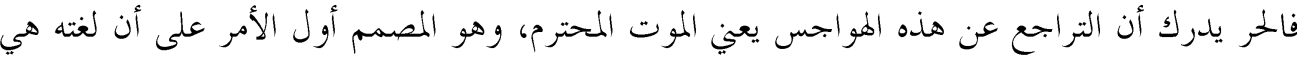

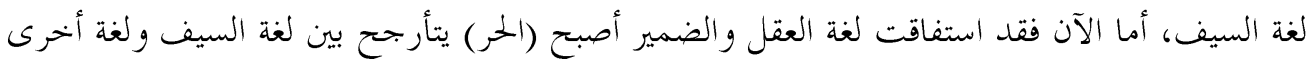

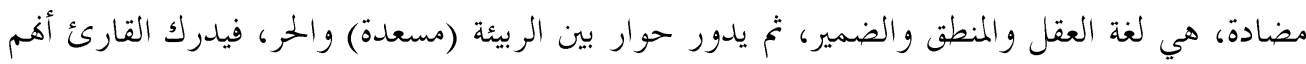

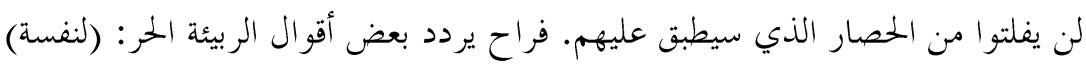
أمنو الموت فانتشروا وفامنتم فجلهم صبية

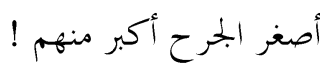

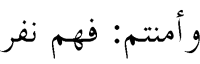

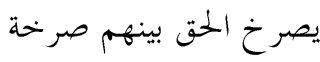

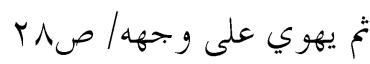

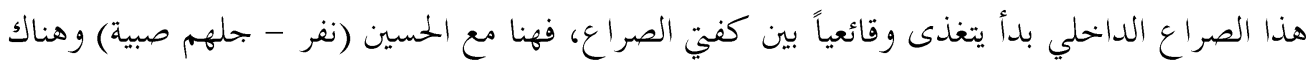

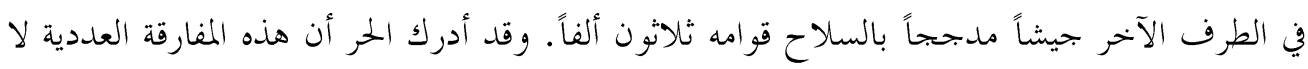

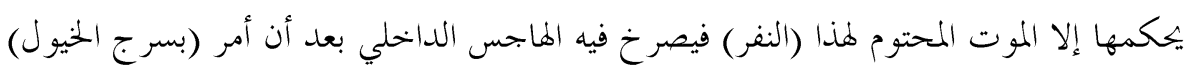

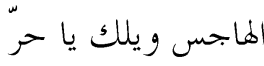

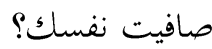

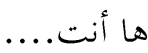
لا سرج فوق حصانك غير المواجس

أنت تخدن نفسك يا حر تملك السيف

لكن مقبضة في يد لست صاحبها ص28، 29

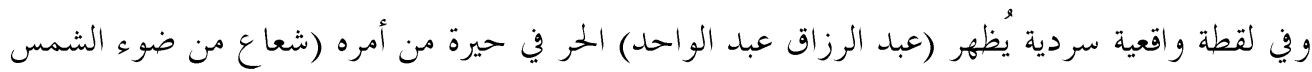

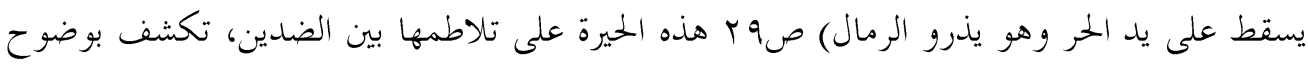


تحو لات (الحر) نحو معسكر الحسين (عليه السلام) من خلال (شعاع من ضوء الشمس يسقط على يد

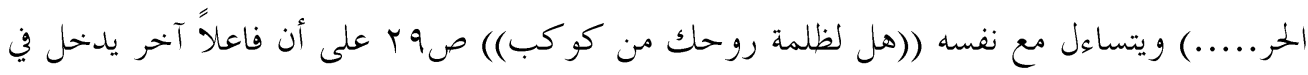

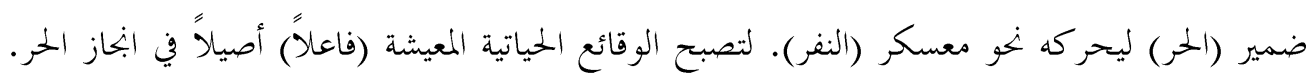

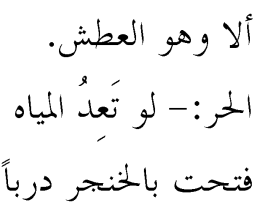
وبعد أن يستدعي (الحر الرجال الذين تحت إمرته، يدور حوار طويل، وكان (الحر) في هذا الحوار يريد

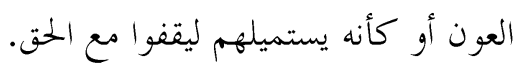
وكأن الحوار بين (الحر) بوصفه الآدمي والهاجس هو الدراما الحقيقية في ذات (الحر) لأن الهاجس هو بهر الصوت الداخلي العميق الغور، وهو المحفز الأساس لبلورة الموقف والدفع به نهو الانتصار للذات

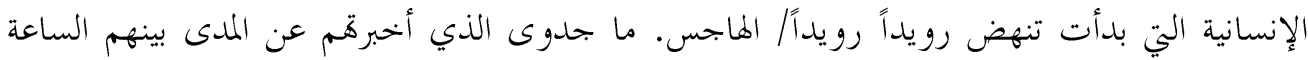
والخسين.

مادام المدي بينك انت و الحسين لا تعرفه؟ ص اسب

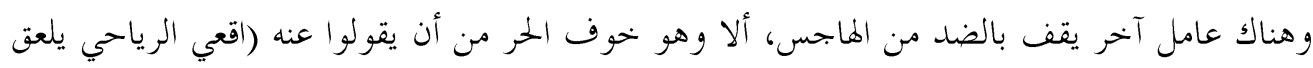
قيح وساوسه) صبr وتثور المواجهة بين الداخل والخارج عند الحر إلى مداها وهو يحاور من بإمرته/ الهاجس:- كن سيدهم وقل أو عبدهم وعبد طغيانك .... واسكت صب ومن خلال الحوار مع (مأموريه) يدرك المأمورون الثلاثة أن في داخل الحر زوبعة من الصراع أبو حفص: يا عمر اهدأ ومن أنأ يخيل لي أن سيوف الأرض جميعاً أنساً تعجز أن تقطع بال أميرك ص35 ولفظه (أميرك) هذه ذات دلالة عميقة لدي (الحر) وعند القارئ، لأن كل الحديث السابق يناديه (بالأمير) أما الآن فهو أميرك، وهذه دولاكة دولة على عدم الانسجام بين الحر (وقواد كتائبه) الهاجس:- أصبحت تبصر في أيما كلمة

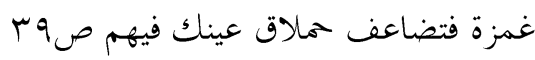


وبعد خروج (المرؤوسين الثلاث - أبو حفص و زياد وعمر) يظهر مشهد آخر يعد رمزاً للإنسانية

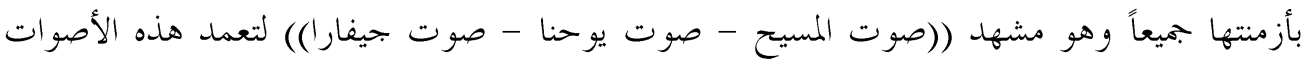
قراره الإنساني. الحر - لا لن تكون سلماً يا حر الإلي.

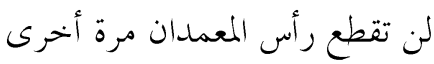
ولن تعلق المسيح (مناديا) يا مسعدة (يدخل الربيئة) الر بيئة: لبيك الحر: أرشدلي إلى مرابض الحسين لينين والآن يا حسين هامة هذي الشمس أدنى إلى سيفي من رأسك ؛ صلك 62 أما مشهد الحارث ابن الحر وابيه فيأتي ليرسخ يقين الحر بأن ما سيقدم عليه هو القرار الصائب والأمين للإنسانية والحق وإن كان مصيره القتل أو الاستشهاد(8). ويلتقي (الحر) (بالحسين) عليه السلام. يهاوره هل لي من توبة، فيحمل سيفه ويقاتل أعدائه حتى يقتل. وهكذا يؤول الصراع الداخلي إلى ساحل الحق والعاطفة الصافية والرؤيا الغيبية البعيدة والإنسانية المبتلات بالظلم والقوة و القهر. إن الصراع الداخلي الذي تلبس ( الحر) كان صراعاً نامياً تسنده الأحداث، كما تسنده الرؤى الحية التي تعيش في الأعماق الغائرة في دواخل الحر، وقد توافق إلى حد بعيد مع ما تفرضه القوان القواعد المسرحية

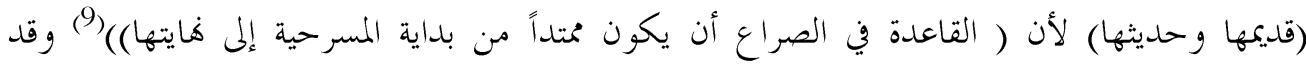
تحققت هذه الخاصية إلى حد بعيد في هذا الفصل، وهو على العموم صراع خالد لأنه يخرج العمل من إطاره التاريخي المحدد بالزمان والمكان إلى كل الأزمنة والأماكن كونه يأخذ البعد الانساني ميداناً 
لقد نمى الصراع في هذا العمل الإبداعي على وتيرة هادئة ومتدرجة، فلم يكن يسير على وفق قفزات

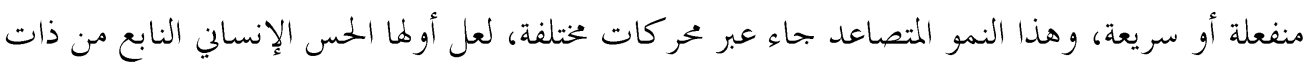

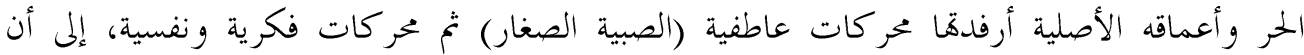
تكاملت ليضع ( الحر) حداً لتأرجحه بين كفيت الصراع، ليصل في المطاف الأخير إلى التخاذ القرار، فهو

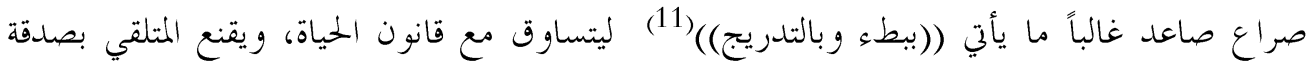
و معقو ليته.

في الفصل الثاني ينهض الصراع على أفت تدميري للذات، وهو وإن كان صراعاً نفسياً داخلياً إلا أنه

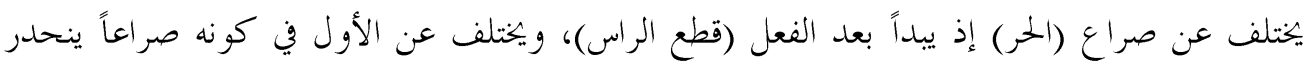

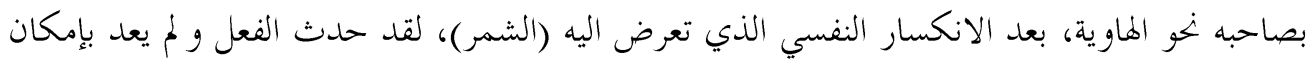

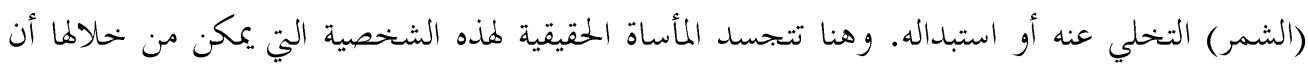
تصل إلى (تطهير أرسطو) وهي نوع من استنطاق الذات العميقة في بعض مفاصلها.

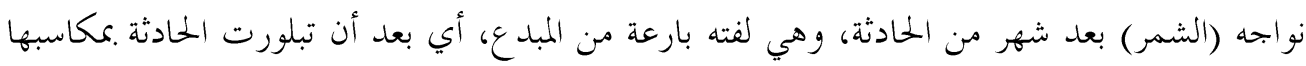

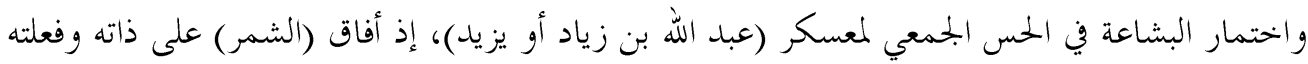
وفي عقله لوثة لا يكاد يخرج من سطوتا، مع تمزق داخلي شل روحهه وعقله وجسده.

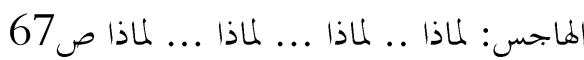
وهذه الـــ (لماذا) هي الكلمة الوحيدة التي قالها الحسين عليه السلام للشمر لحظة قطع رأسه، فهي التي خلفت الرعب والخوف والهوس في داخله بعد أن أفاق من الجلبة التي أحاطت به بعد مقتل الحسين عليه

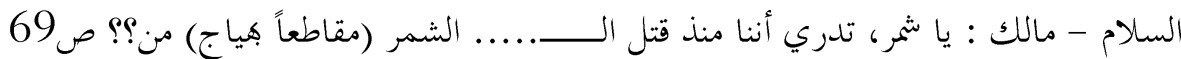

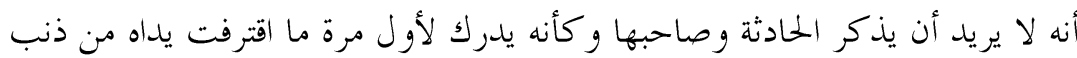

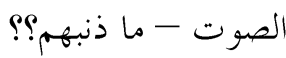
أتراني أقطر هذه المرارة أعصرها من حناجرهم بطراً لا .. و خسئت إذا كنت أفعلها سأكدر هذا البياض وشسئ إداض أرغم هذه الأصابع المريبة

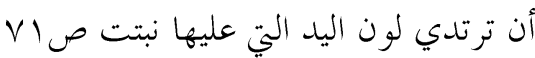


وهنا نكتشف إلى حد ما دواخل (الشمر)، فلديه عقدة داخلية عاشت وتربت على الكراهية والظلم، و الحقد الأسود، والبشاعة .... ولكن من الذي ربي هذه الأوصاف في داخله، أهي السلطة، أم المجتمع؟ هذا ما لم تكشف عنه الحوارية، وكنت أتمنى على (المبدع) لو أنه أشار ولو من بعيد إلى مسببات هذه رئ

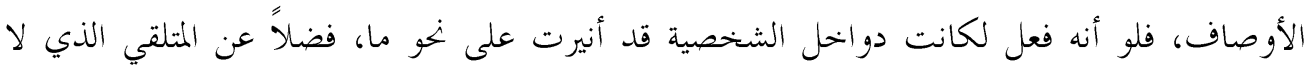
تستقيم أمامه الأمور. الشمر: (يتتفض من مكانه مفزعاً و يتجه إلى الكف) الكرون) ها أنت ذي سهيل: يا شمر مالك: (يمسك بسهيل مقاطعاً)

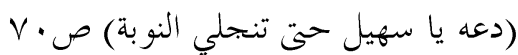
إذن فهي نوبة هستيرية لا يقوى على الإفلات منها بعد أن رأي اليد من خلال الخيال الذي يتعقبه أينما

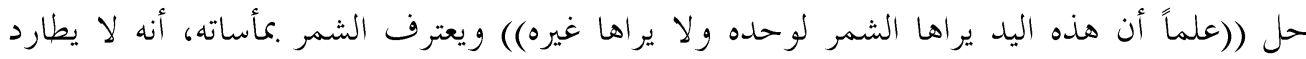

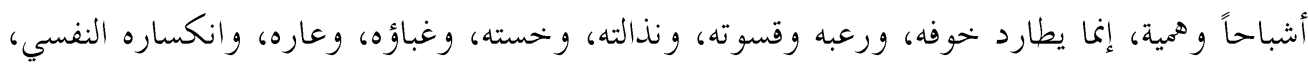
من خلال الأشباح التي تطارده مالك: أجننت تطارد أشباحاً

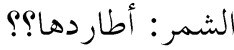

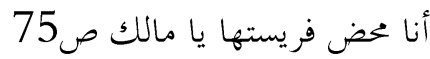
و يأتي الحوار مرة أخرى ليكشف عن عمق المأساة في دواخل الشمر فقد استهلكته الجريمة بكليته

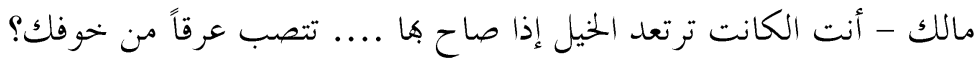

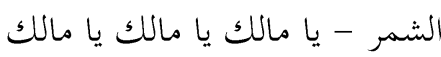
تعير مثلي بالخوف ضع قبلي الموت أفعى ها ألف رأس .... أقاتلها الآن

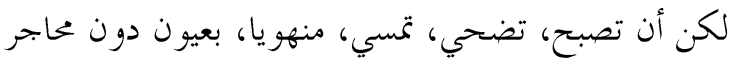

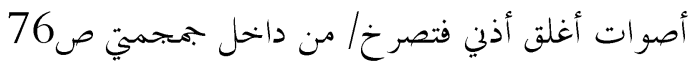


أن اسلوبيه التكرار في قوله ( يا مالك) ثلاث مرات تظهر عمق القهر الذي يعشعش في الذات العميقة،

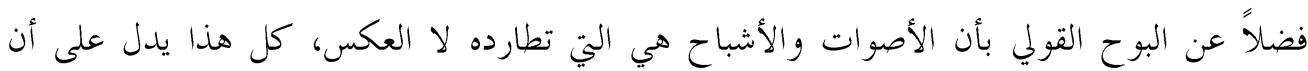
(الشمر) أصبح خارج نطاق الوعي الإنساني الطبيعي، فهو مسكون بما فعلت يداه، و لم يبق بينه والجنون إلا خيط رفيع أبقاه (عبد الواحد) لكي يكمل رؤياه الفنية والفكرية.

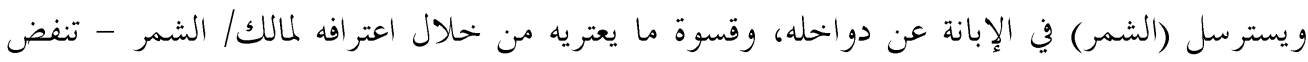
الغيمة المدلهمة أمطارها البراكين تفرغ أجو افها ثم محدأ أنا مثل البير كلما أخرجوا منه يزداد النير عمقاً كلما أخرجوا منه يطفح الماء وأن تتناسل في جوفي النار

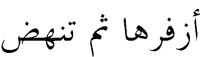
أزفرها و تنهض ازفرها ..... صوهن

في الأسطر الثلاثة الأخيرة يظهر تضائل صوت الشمر على مستواي بناء الجملة دلالة انكساره الداخلي.

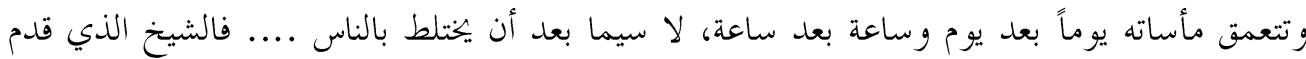
اليهم يسأل الماء من شدة العطش، لكنه يرفض أن يشرب بعد أن عرف (الشمر)

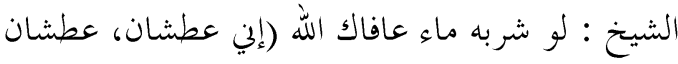

$$
\text { الشيخ : أنت ابن ذي الجوشن؟ }
$$

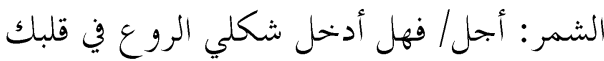$$
\text { الشيخ: كلا ! الش }
$$

الشمر: إذن فيم رددت الماء؟

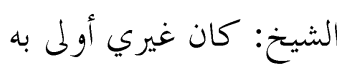

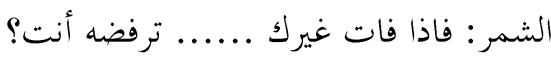

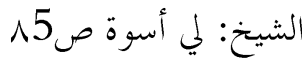


وهنا تتجلى التراجيديا في أهىى صورها عندما يكون (الشمر) مأخوذاً من الداخل ومن عامة الناس

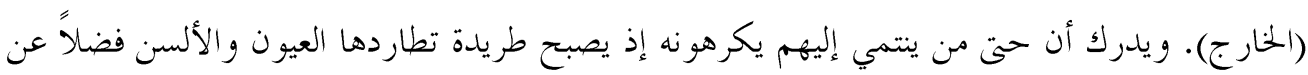
مطاردة الذات العميقة مالك: لكنك كنت الأقوى

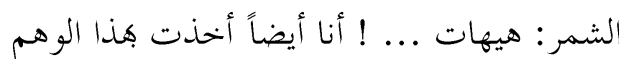
كان ورائي ثلاثون ألفاً

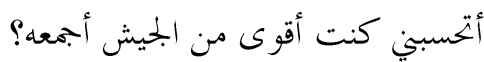

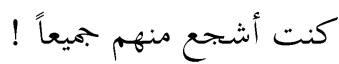
أحجموا وتقدمت كنت ضحيتهم وضحية خستهم كلها الآن يا مالك أدري فيم تلد غ العقرب نفسها إذا ما حوصرت

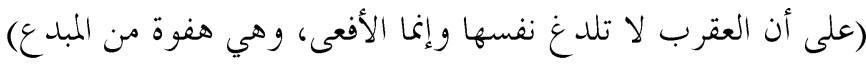
كنت محاصراً بهم كانو إميعاً يندبونين لقتل الحسين

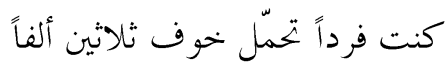
وتحمل جبن ثلاثين ألفاً صع4 84، 85 وفي موضع آخر يقول: ((كنت أحس كراهية الجند لي)) ص105 ويبقى صراع (الشمر) مع ذاته متوثباً

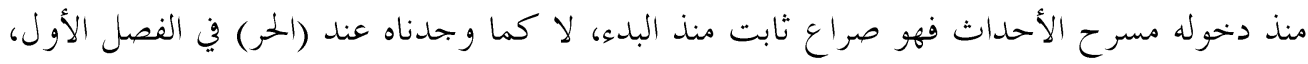

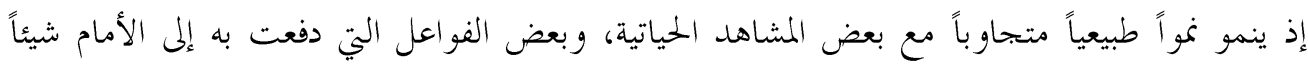

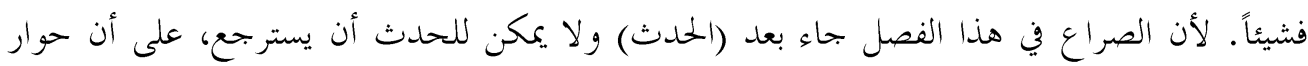

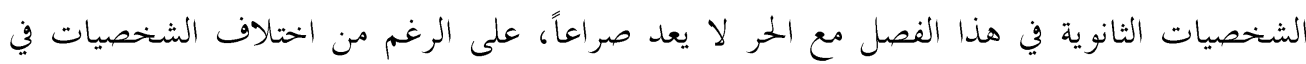

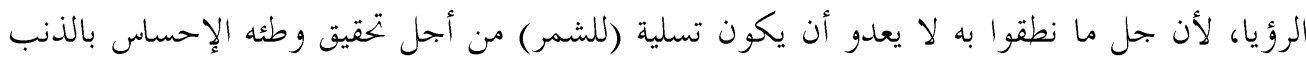
الذي يعانيه. 


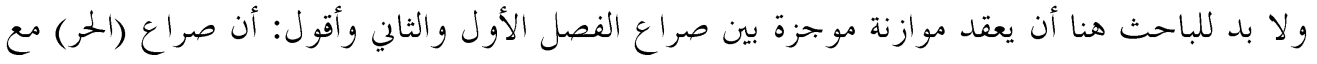
ذاته كان صراعاً نامياً أوصله إلى القرار لأنه كان قبل حادثة (القتل) في حين بقي صراع (الشمر) جامداً لم يتبدل إلا في حالات نادرة، وهو عبارة عن (فلاث باك) غير مرئي، لأن (الشمر) يسترجع الحوادث فيثور في داخله الصراع. أما المسالة الأخرى فقد كان صراع (الحر) قد أوصله إلى التخاذ القرار في حين لا بند مثل هذا القرار عند

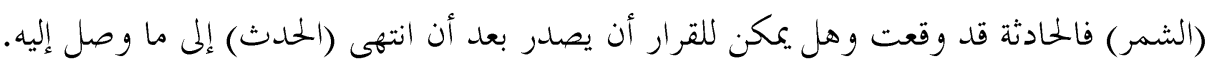

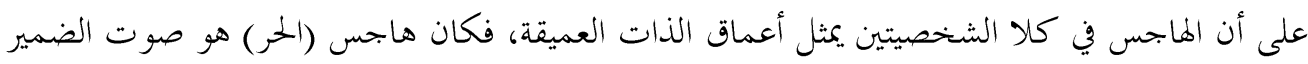

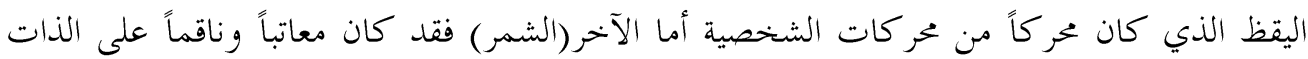

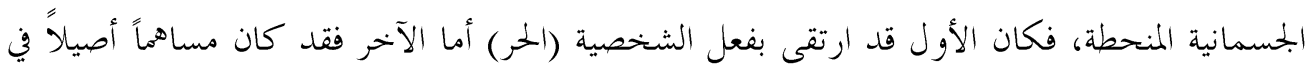

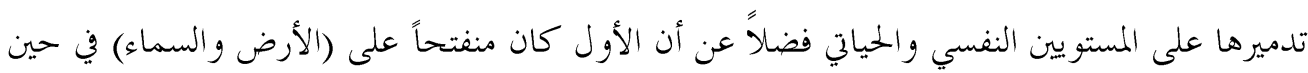

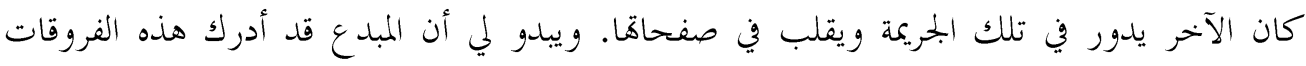
الجوهرية بين الفصلين، فانتمت المسرحية في عنواها إلى (الحر الرياحي) و ولم يترك (للشمر) في هذه بهن

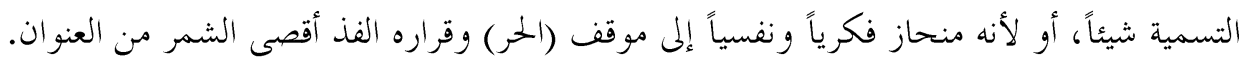

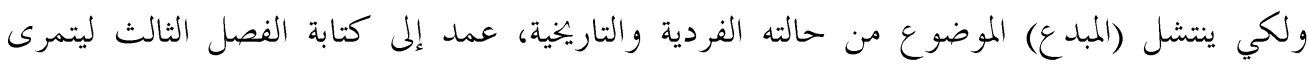

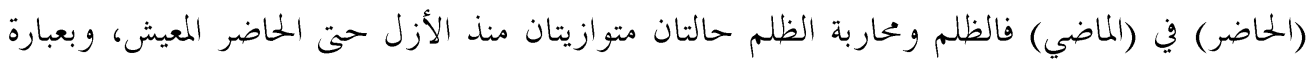
جبراً فإن (المبدع استطاع أن يستخلص ل... من قضية تاريخية كبرى بعضاً من إشكالاها النفسية الباقية في كل عصر))(12) وعلى هذا الوصف استطاع أن ينجز (المبدع) تراجيدياً شاملة لكل العصور

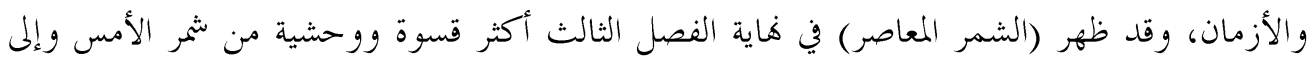
جانبه ظهر (الحر المعاصر) الشاب: إذ كنت حقاً تحاول أن تلتقي الحسين لتقتله ثانية الشمر: (مقاطعاً) بل سأقتله ألف مرة صأفال 160 وهذا الفصل يعد استنساخاً مضمونياً للفصلين الأول والثاني، فالمبد ع يسقط الحاضر على قوانين انسانية

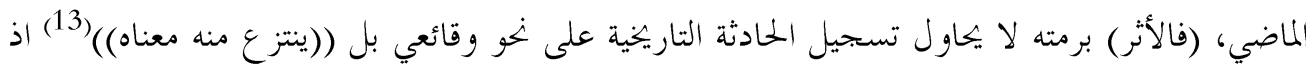

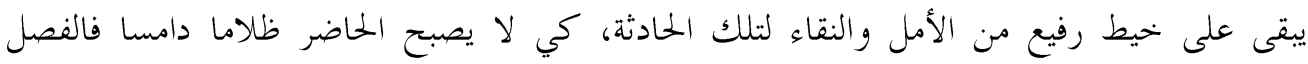
يتحدث عن ( التشبيهات) ويقاطعها مع حقيقة انسان الحاضر الذي لا يراه الاصورة من ذلك الماضي. 
فبينما عمار وحارث ومعتوق يحاولون جمع تواقيع الناس لمبايعة الحسين وهذا مشهد من التشبيهات يتقدم الأفراد والقبائل لتسجيل اسماؤهم، بتقدم ثلاثة أشخاص حفاة ليعلنو ا البيعة وهم يرددون الثلاثة: من يكتب عنا؟

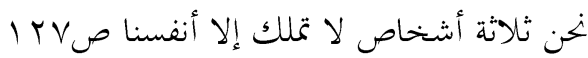

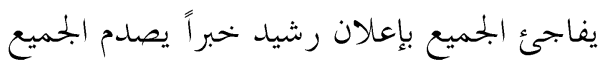

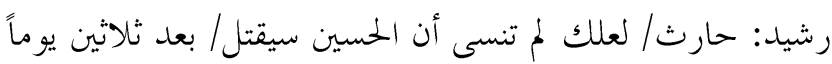
أصوات: مكيدة أذن. آخرون: مكيدة مدبرة ((يهجمون جميعاً على حارث)) هات أسماءنا المهاجمون: سعيد/ انتزع الأسماء من يديه (يتمكنون من حارث فينتزعون منه الأوراق) (ويخرج من المسرح جماعات هاربة) (و يبقى في المشهد عمار وحارث والحفاة الثلاثة)

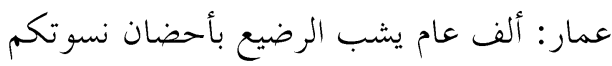
وهو يحلم أن يرتدي كفناً ليقاتل عن شرف باعه أهله

كيف يدخل داخلهم بيته الآن؟ (يلتفت إلى الحفاة الثلاثة)

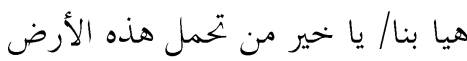
رشيد: أتحسب أنك تنجو هئ بهم؟ سوف نقطع أعناقهم قبل أن يبلغوا مدخل السوق/ وأنت على رأسهم الثلاثة: أسعع يا هذا/ نعلم أنا سنموت/ بايعنا في الطف ومتنا بايعنا في سيناء ومتنا بايعنا في تل الزعتر أمس ومتنا بأبنا

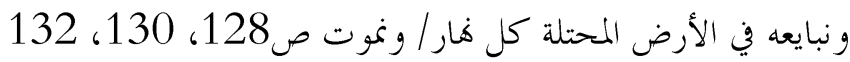
ولكي يجعل ((المبدع)) المأساة والتراجيديا الإنسانية مستمرة لا يحدها زمن ومن بعينه أو مكان بعان بعينه، يعيد المعمدان ودليله في المشهد الأخير، والأمل يتبرعم فيهما. بصيغة المجاز عن ((الانسانية)) كلها. الدليل: ألمح راية على رابية مرفوعة 


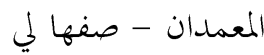

الدليل: على ذروها هلال/ / وحوها تموج موجاً جثث الرجال المال كأنما كبّ تحت ظلالها بلال

المعلدان: ما لو كاب

الدليل: سمراء كالرمال/ ممراء كالرمال/ بيضاء كالرمال

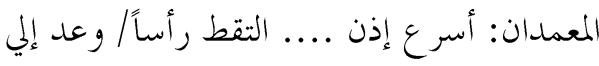

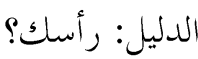
المعمدان: هذه كلها رأسي/ أدر كتها

(ستار)

وعلى وفق هذا الوصف يصبح (الحاضر) صورة بحسمة (للماضي) وهي أكثر تدميراً وقسوة، ربما

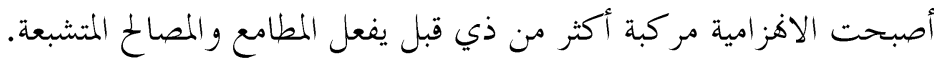

$$
\text { الحوار .... ولغة الحوار ..... والدراما }
$$

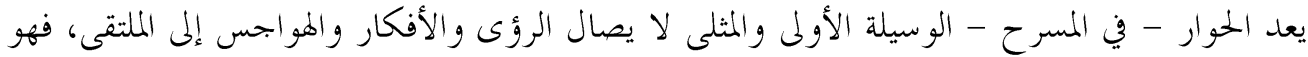

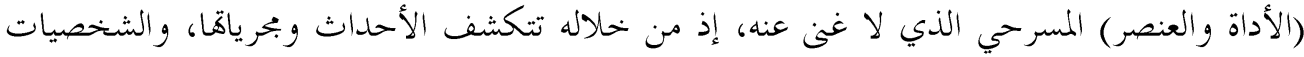

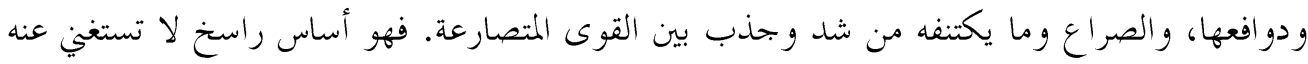

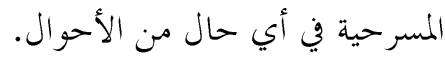

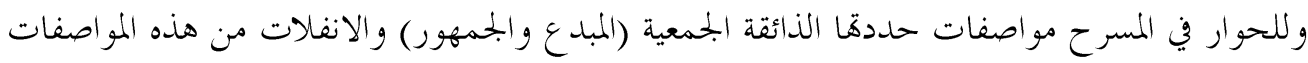
يبدو بعيد المنال - باستثناء الانخر افات البسيطة والتقنيات المستحدثة التي تغنين ولا تلغي.

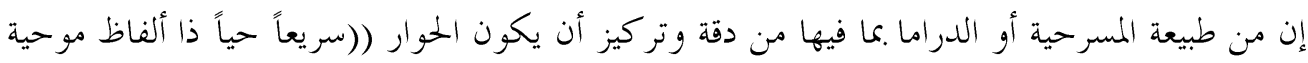

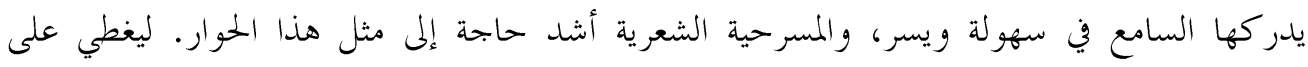

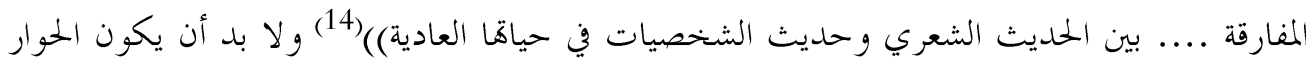

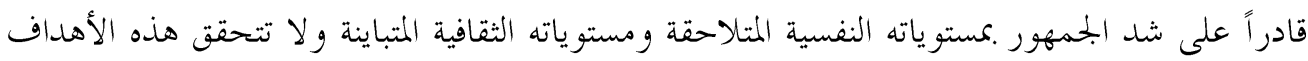

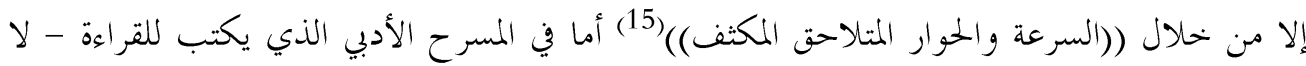

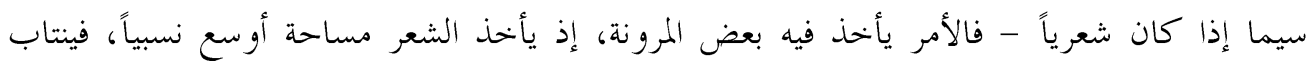

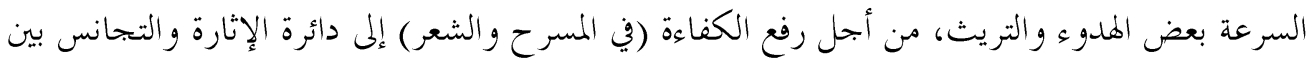

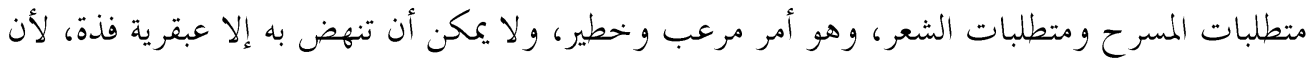

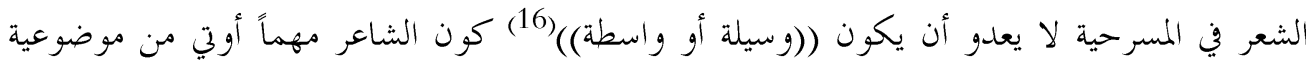


إزاء الحدث، لا بد لفورة الشعر أن تطل برأسها إزاء موقف أو شخصية أو مفارقة ما ولا بد لها أن تخرج بعيداً من منظومة المسرحية (الأحداث - الشخصيات - الصراع) فهذه المنظومة محكومة بذائقة الجمهور

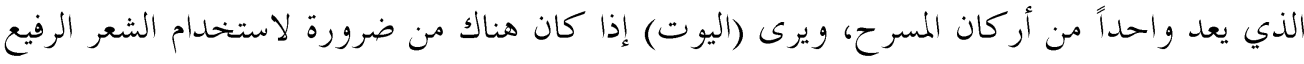

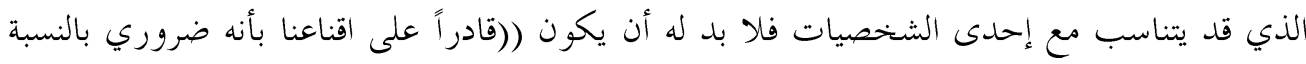

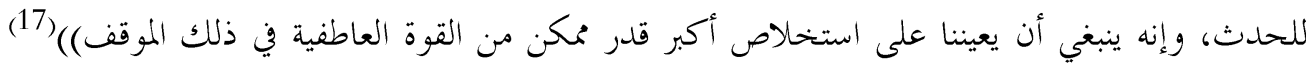

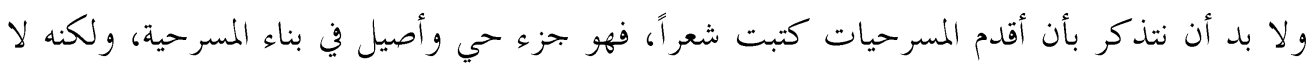

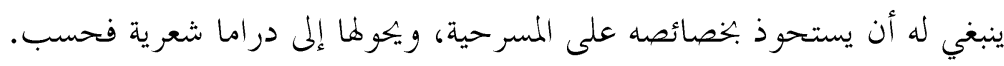

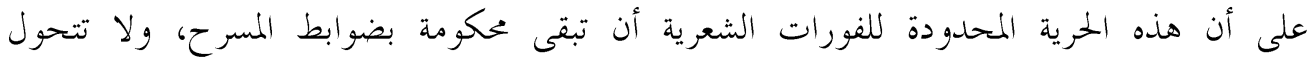

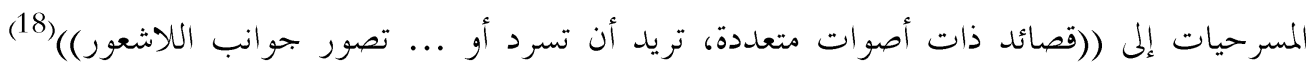

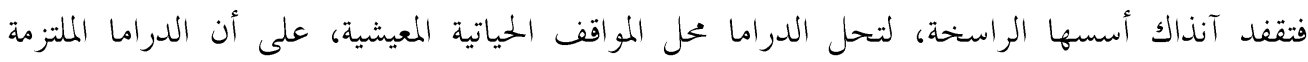

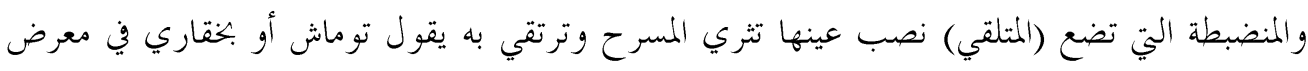
حديثه عن الدراما (لقد خرج علينا كل من تشيكون وبرنادشو بطريقة في التفكير، الأول في بحال النفس الداخلية .... و واستطاع كل من زاويته أن يرقي بمستوى عناصر التفكير ويغني ويثري من شاعرية المسرح))(19) ويضيف (( أن الطبيعية تنادي بالمواقف الحياتية والواقع إلى خشبة المسرح لإبراز الحقيقة

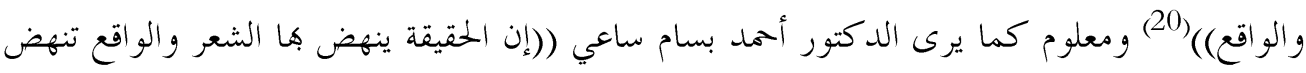

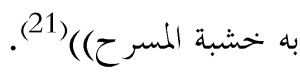
على أن الحوار الناجح لا ((يأخذ صورة سؤال وجواب بين شخص وآخر، لكننا نتظر كما نتمثل

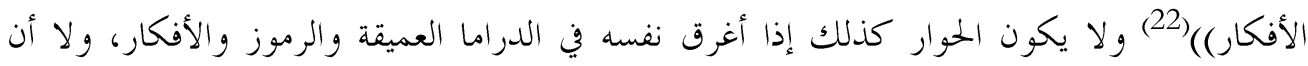
يكون خطباً رنانة أو قصائد شعرية مطولة تستعرض لغة الشاعر، إذ لا بد له أنه أن يتسم ((بالإيجاز والأحكام)(23) على قدر ما يلبي متطلبات الأحداث والشخصيات وبذلك تصبح اللغة لغة واقعية أدبية أي أها على قدر حاجة المسرحية - لأن الأساس في لغة المسرحية الشعرية ((ألا يحس المشاهد أن حاجزاً

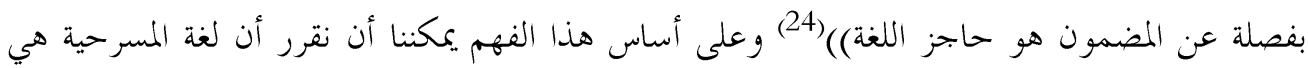

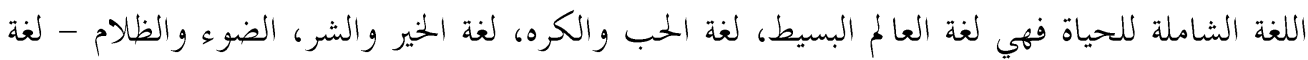

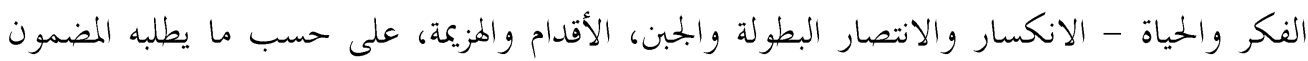

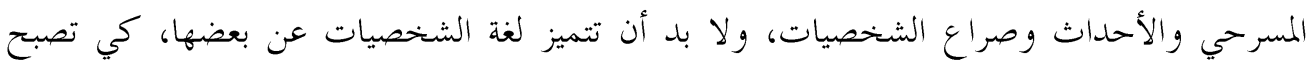

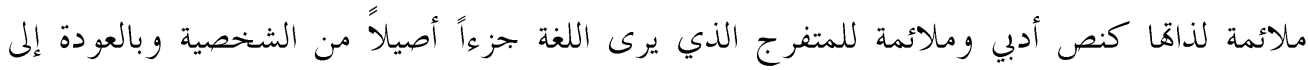


المسرحية لتفحص حوارها ولغتها يمكننا أن نقرر منذ البدء بأذا لغة الشاعر، وليست لغة شخصيات، إذ

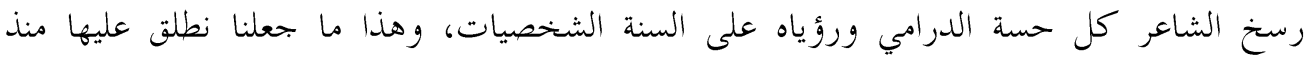

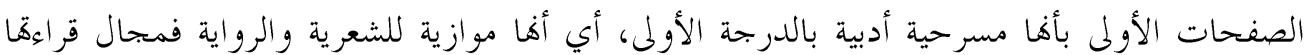

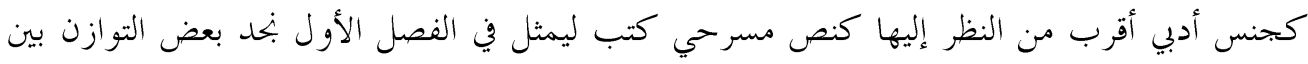

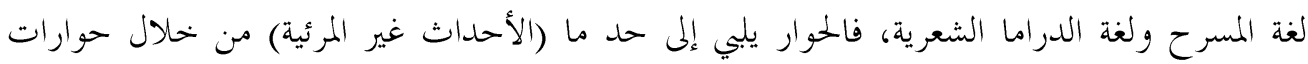
الشخصيات مع بعضها، إذ تتوافق مع هذه الأحداث وتكشف عن تفاعلات الشخصيات ومواقفها، في

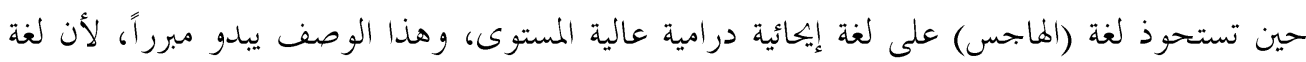

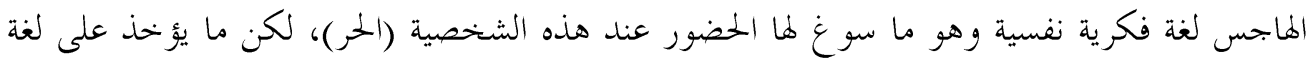
الهاجس استطالة جمالها وبو حها، مما يجعلها ثقيلة بعض الشيء، فلغة المسرح على ملى سبيل المثال لا الخصر تتمثل في هذا المثنهد غير المنتخب الذي يعجب المتفرج: الحر: ماذا وراءك الربيئة: ابشر

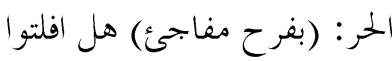
الربيئة: حاشا (الثر الحر: أوجز إذن إناتن

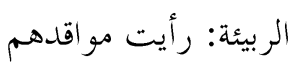
الحر: خمدت؟ نمبك الربيئة: ما يزال الرماد بها دافئا وفي مشهد آخر نقرأ أبو حفص: من أمس وشيء يشغل بالك يا حر الحر: أجل ألمهل زياد: مر، اقطع عنق الصحراء الساعة/ ما تتزف هاجسه

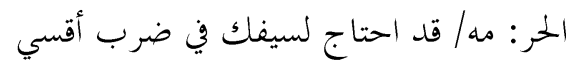

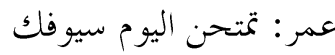
الحر: مهلاً أبا حفص/ لو أنين أمرت أمراً الساعة/ هل انتم مخالفوه؟ أبو حفص: حاشاص 38 - 42 
فالحوار في هذين النصين قصير متدفق، ندرك من خلاله بعض الأحداث، وما يعتمل (الحر) من هموم

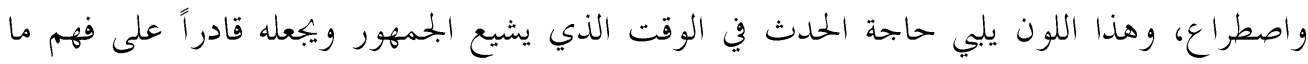
يدور. أما اللغة فقد جاءت ملائمة للأحداث مع قدرها الفائقة على حمل الكثير من الإيحاءات التي تكشف عن دو اخل الشخصيات (الايجابية والسلبية). أما حين ننتقل إلى لغة (الهاجس) - وهو صوت الحر الداخلي - نطالع لغة أخرى مكتتزة بالشعرية والدراما النفسية. وقد تطول لتأخذ من الوقت الكثير الكثير فيتوقف الزمن، وتتوقف في الوقت نفسه حركة الأحداث الهاجس: إذا لحظة الصمت/ فلتختصر كلماتك أنفسها/ تتراجع؟/ أم تقتل

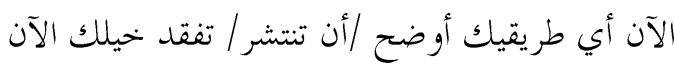

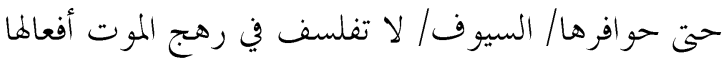

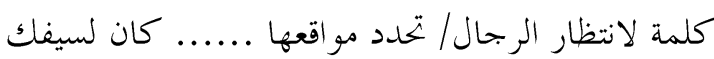

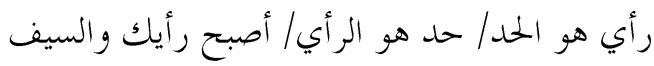

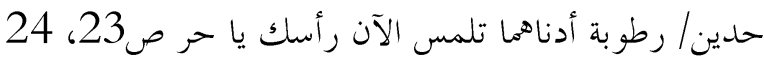
إن هذا (الهاجس) على ما يحمله من لغة سامية مدارية إيهائية، غنائية درامية، لا يتحملها المسرح، وهي صي

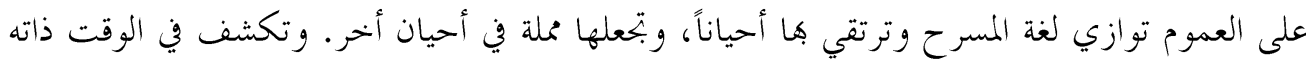

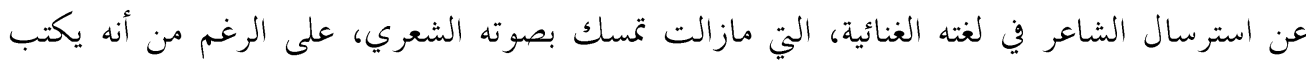
للمسرح الذي يتطلب موصفات خاصة وحاكمة. ترغم الشاعر أن يتنازل عن ذاتيته الحرة. في الفصل الثاني المخصص (للشمر) يصبح البون شاسعا بين نوعين من الحوار (حوار الوقائع - حوار

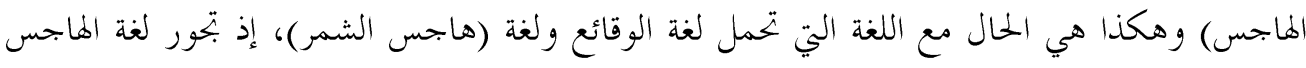

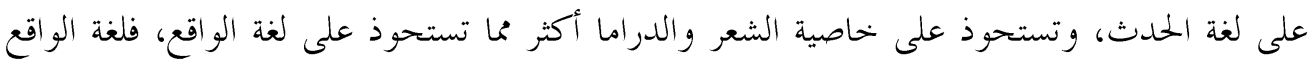
تحمل صفة التعالي والقوة والسطوة والقسوة لكن لغة الهاجس وحواره كانا بالمرصاد لهذه اللغة المتعالية،

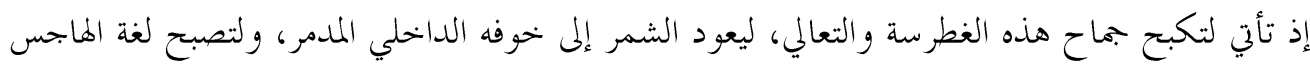

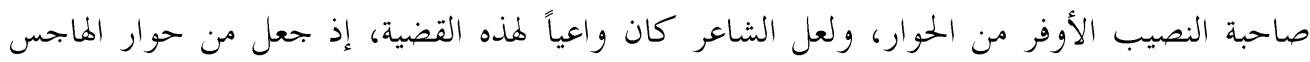

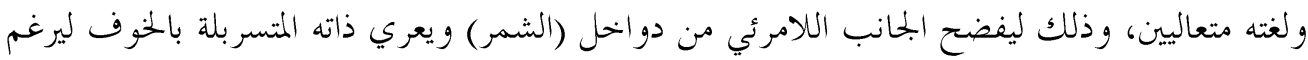

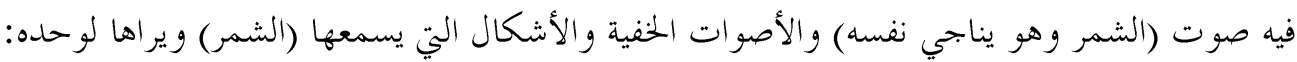


الشمر: " يتتفض من مكانه مفزعاً ويتجه إلى الكف التي لا يراها إلا هو " ها انت ذي بيضاء حتى العظم/ تخترقين الباب والجدار وتملئين الدار/ تروعين يقضي ترو عين نومي/ ستبيتين بين عينيّ إلى القيامة.

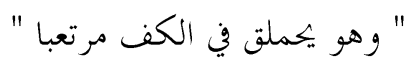

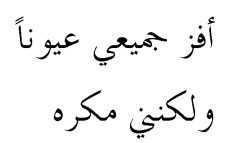

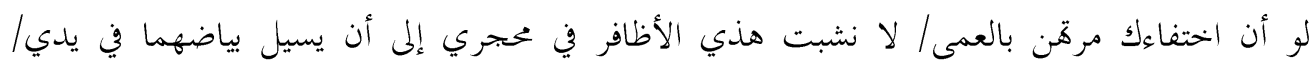

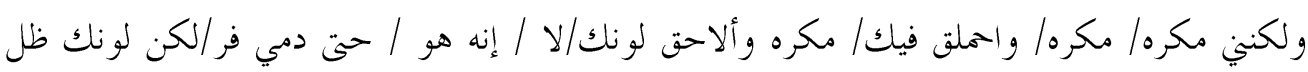

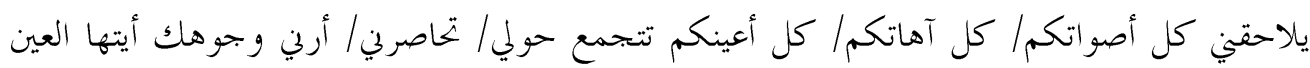

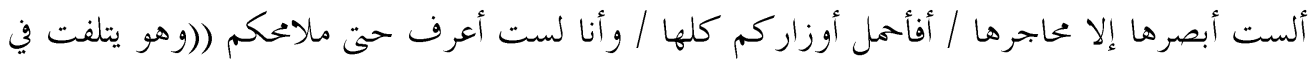

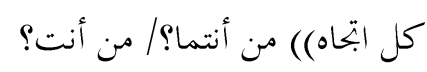

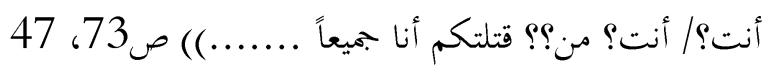
إن هذا المقطع المقتطع يكشف على نحو لا لبس فيه الرعب الذي تلبس (الشمر) فأصبحت هلوسته أقرب

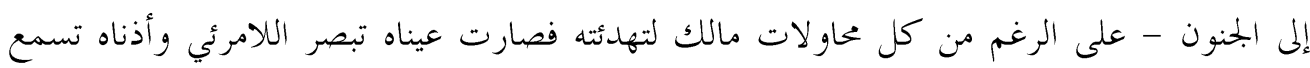

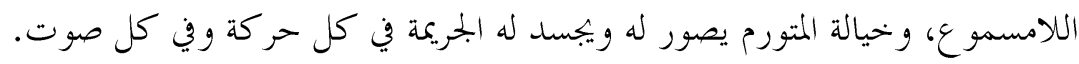

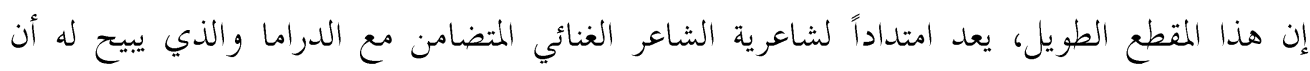
يسترسل ما شاء له ذلك.

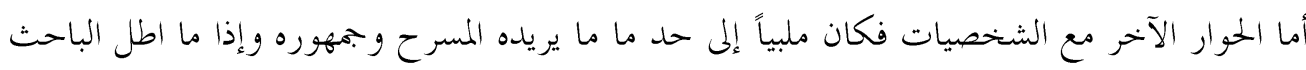

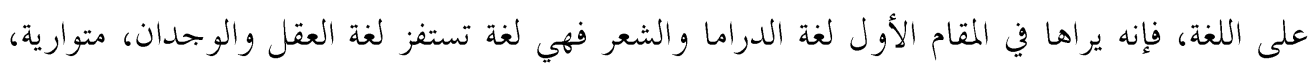

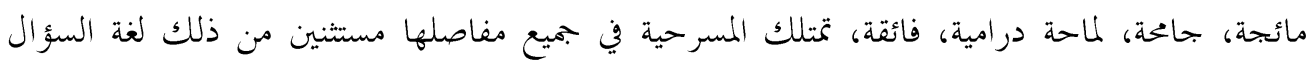
و الجواب - تصرح وتلغز، وتبوح وتلمح، مع ما تحمله من لغة البيان العربي التي ترتفع بقيمتها الشعرية - بعيداً عما يتطلبه المسرح. إن لغة أي عمل أدبي أو جنس تنبع من دواخله، من عمق مغزاه، لا تكون طارئة عليه أو تأتي من

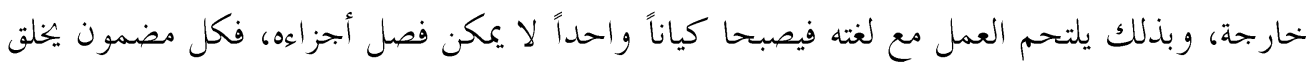
لغته، وقديماً قرر الجاحظ أن الألفاظ والأساليب تأتي على قدر المعاني ((فالسخيف للسخيف، ولهيف والجزل

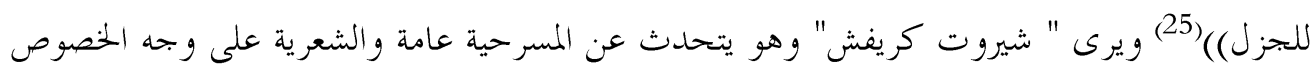

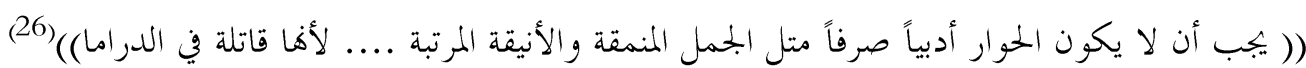


والنصان السابقان يؤكدان تطابق اللغة مع المضمون لا سيما في الدراما، لأن الجمهور يتلقاهما سوية (السمع و النظر)، فاللغة على هذا الوصف تخرج من رحم العمل، من روحهه، من معاناته، من مضمونه

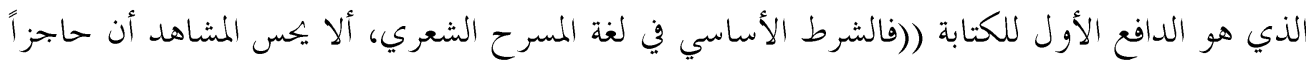

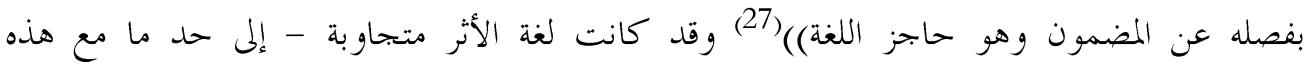

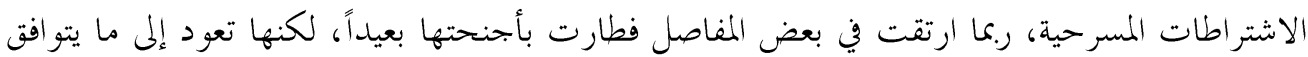
مع الشخصيات ولأن الشخصيات المسرحية ليست شخصيات عادية، لأن كل منهما يحمل رؤيته

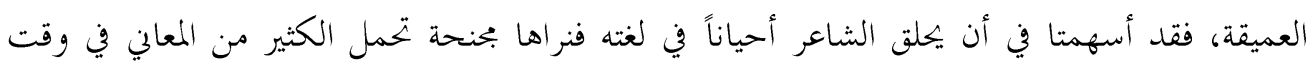
و وإن كان لا بد من التدليل على هذا الوصف، فحري بالباحث أن يتفحص هذه اللغة في سياقها الذي جاء من خلاله، مع كشف بعض دلالاتا المعنوية والأسلوبية، وبنيتها العميقة في بعض جملها ذات الدلالات العميقة ((عقرب نضرب الليل بين ضلوعك - ماكولة الظهر - أن تنتشر)) صباء صب يكني

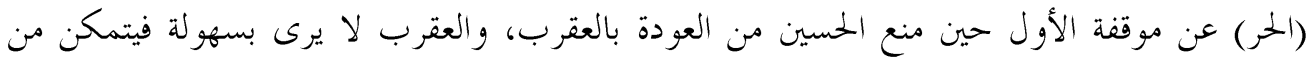

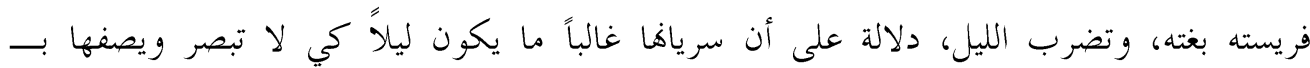

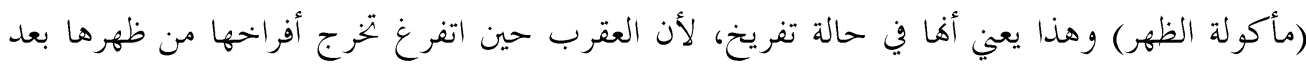

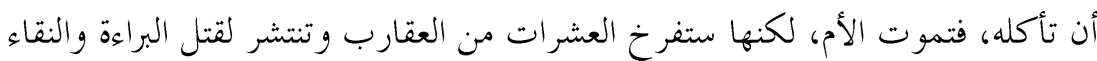

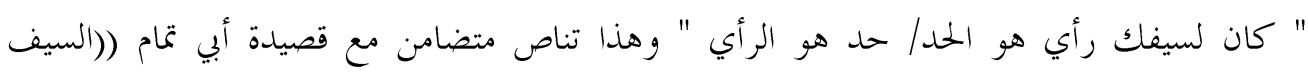

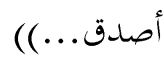
((أصبح رأيك والسيف حدين/ رطوبة أدناهما تلمس الآن رأسك يا حر)) ص24 والحدين هما

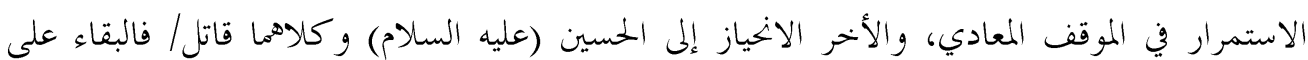

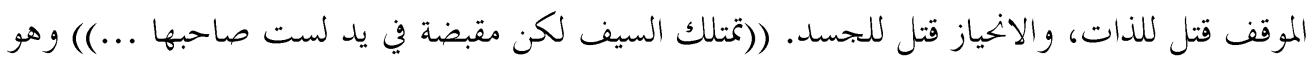

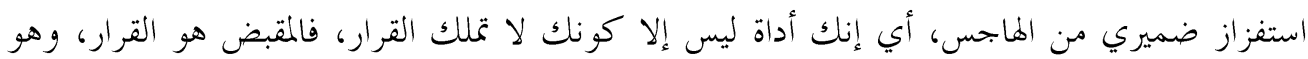

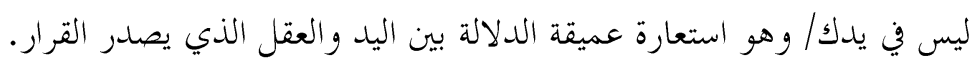

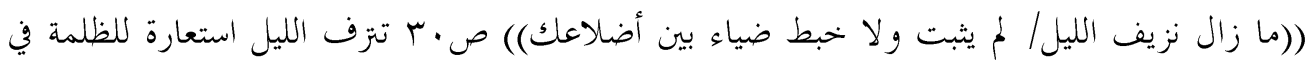
داخله والحيرة، وهل الضياء يشرق أو ينبت وخيط الضياء ((ثم يقولون) اقعي الرياحي يلعق قيح و ساوسه)) ص بr و اقعي هي للكلب حين ينكسر أو يهزم فيجلس. 
((أن بتس الوتر اللين من نفسك/ مثل امرأة تبكي)) صبس والتوتر اللين يقابل العطف والرحمة والوتر

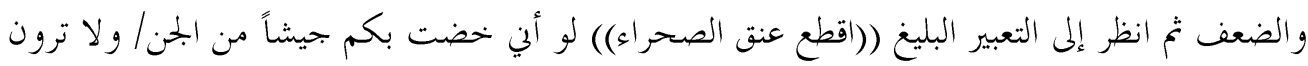

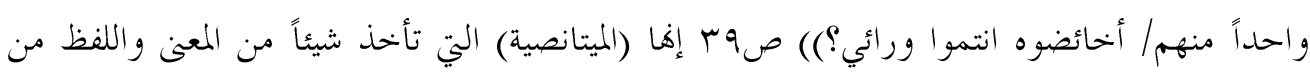

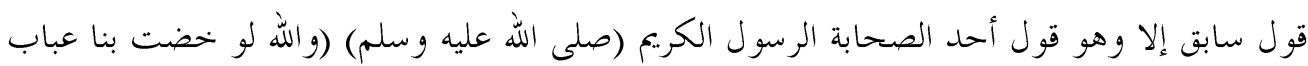
البحر لخضناه معلك)

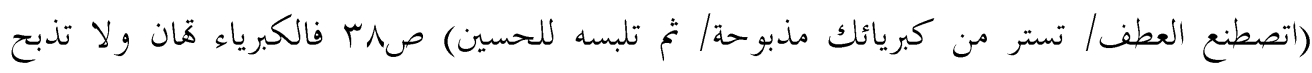
(استعارة) والكبرياء هو ما عليه (الحر) من المتزلة المرموقة في قومه. ولنتمعن في هذه اللغة المكثفة ذات لهات

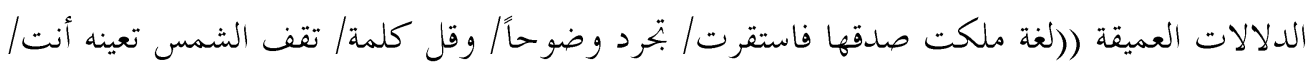
لو لا أضاءت مسافة ما بين قلبك والشفتين)) ص. •ـ أها لغة الدراما وما تحمله هذه اللغة المكثفة الناغزة

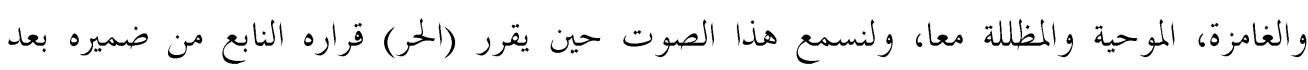

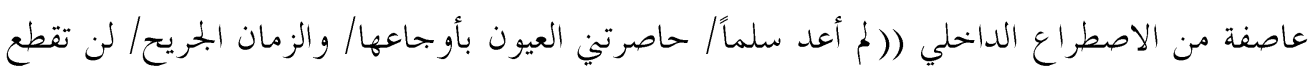

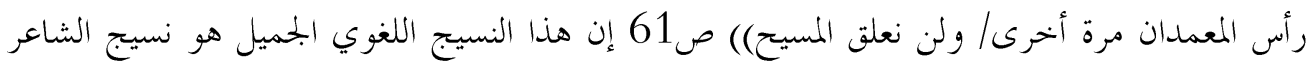
الدرامي و الغنائي معاً. ولنقرأ بعض هو اجس وتفوهات والفي معان (الشمر)

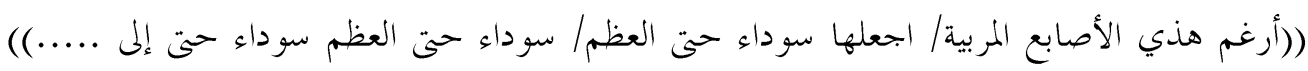

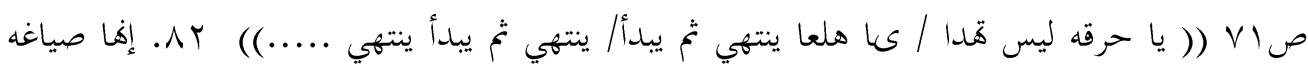

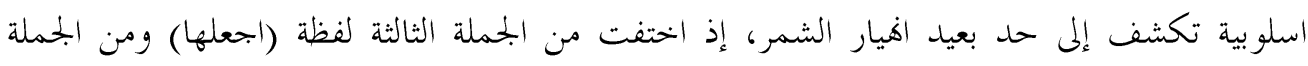

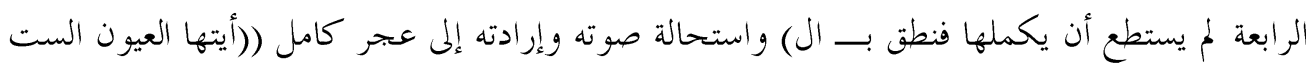

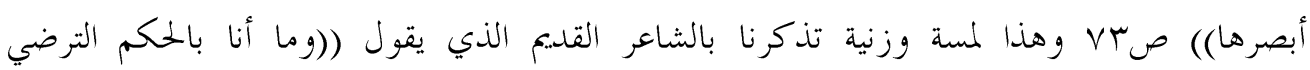

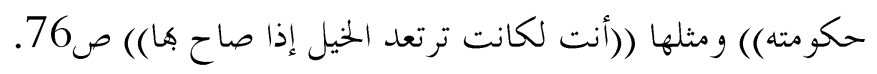
وفي لمحة خاطفة للموازنة بين لغة (الحر) ولغة (الشمر) نقر أنقأ

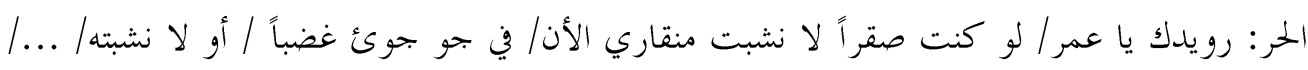

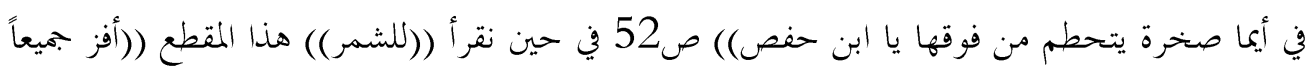

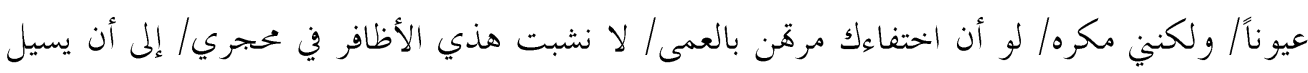

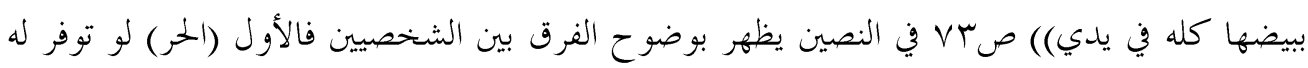

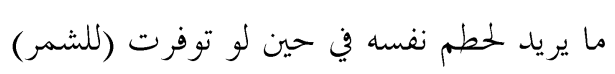


ما يريد لفقىء عينه فقط، فالأول لا يتشبث بالحياة في زحمة صراعه النفسي أما الثاني فهو متشبث ها

$$
\text { فهو لا يزيح إلا ما يؤرق حياته (عينه). }
$$

لقد وفق الشاعر عبد الرزاق عبد الواحد في اختيار شعر التفعيلية (الحر) في بناء نصه الدرامي، لأن

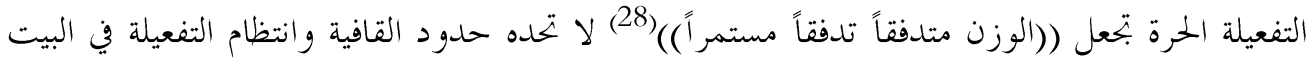

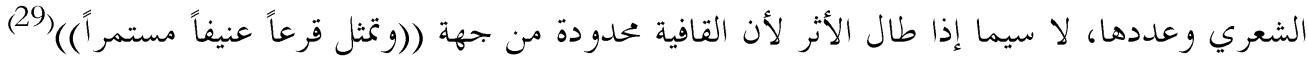
لذائقة المتلقي، لا سيما في المسرح الذي يميل إلى تمثل الحياة العادية. إن مأساة (الحسين) عليه السلام لم تكن مأساة عادية، فهي مأساة دينية، اجتماعية خلقية، عقائدية،

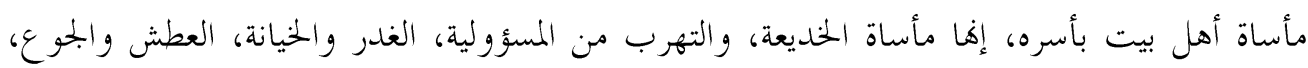

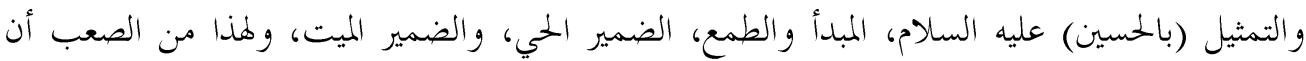
يتصدى مبدع لكل هذه المآسي المتلاحمة في عمل مهما عظم قدره، وقدرة مبدعة، (فالحسين) عليه

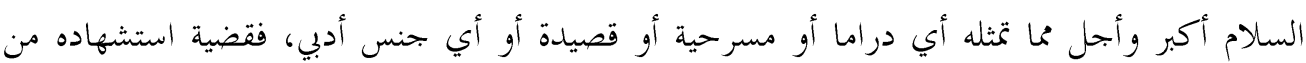
العمق، وما يكتنفها من الألم، ما يجعل العمل مهما عظم لا يوفيها حقها.

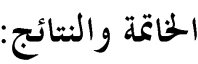

بعد هذا العرض الذي حاول استنطاق الأثر الأدبي على نهو شمولي لأشكاله كافة وبناه ومضامينه، يمكن أن تسجل النتائج التي توصل إليها البحث: إن هذا ((الإبداع)) حاول مخلصاً أن يتخطى الحلدود الصارمة بين الأجناس ويصهرها في في بودقة واحدةة،

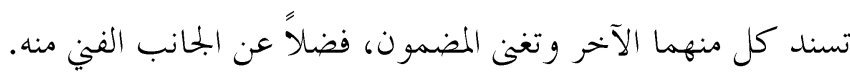

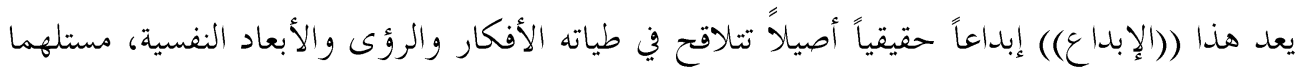
من المسرح حواره، ومن الشعر كثافته وبوحه الحر ومن الدراما الصراع بين الأقطاب المتعارضة.

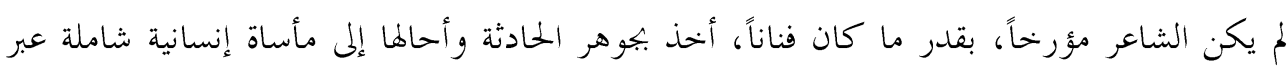

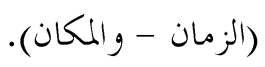

إن التداخل بين الأنواع الأدبية الثلاث كان إلى حد ما موفقاً، فالتداخل كان واعياً الاشتراطات كل نو على الرغم من أن (عبد الرزاق عبد الواحد) شاعر آ غنائياً في المقام الأول، إلا أنه لم ميجعل للشعر الغنائي

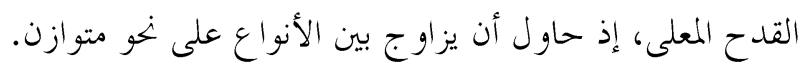


حاول(المبدع) أن يتخلص إلى حد بعيد من الغنائية الشعرية التي أمسكت بزمام الشاعر العربي منذ القدم،

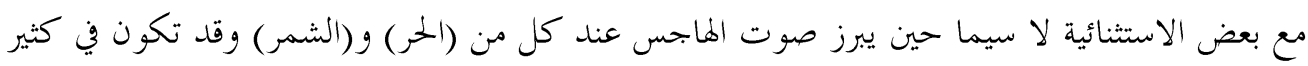
من الأحيان مبررة ومقبولة، كوها تكشف الاصطراع الداخلي عند كلئ كلانها.

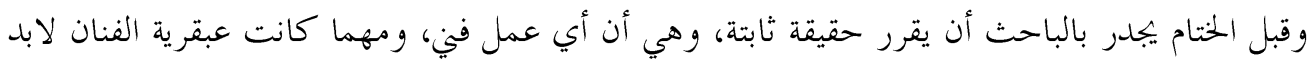

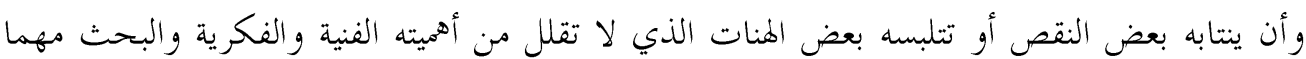

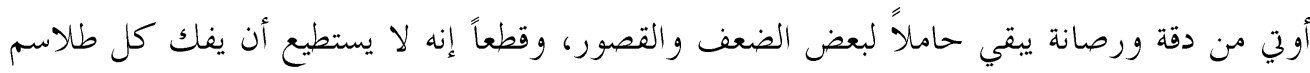

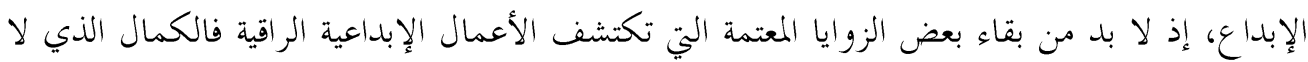
يناقش في الآثار الإبداعية أمر مستحيل ولا يخلو منه إلا ((القران الكريم)).

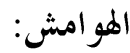

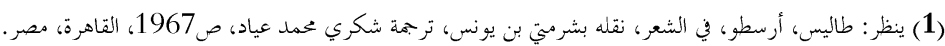

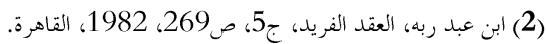

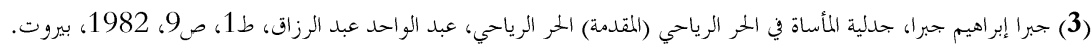

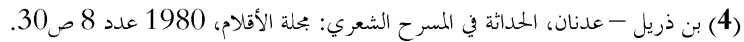
(5) عبد الواحد، عبد الرزاق، صرئ (40، سابق.

(6) س. ك. د، المسرحية من منظور اليوت، ترجمة هاشم كاطع لازم بحلة الأقلام، 1989، 198، عدد 4 صان.

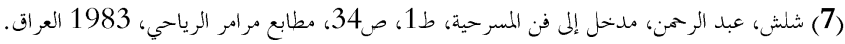

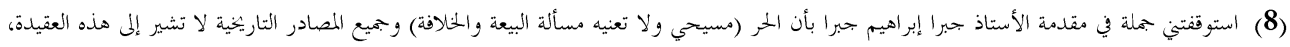

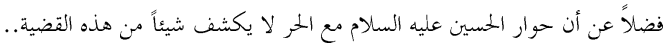

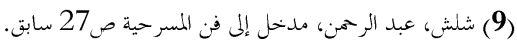

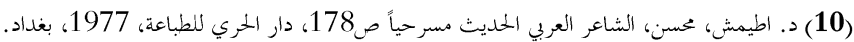

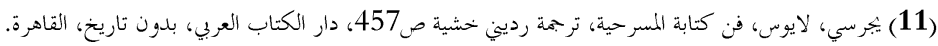

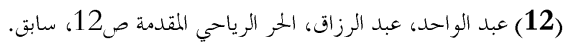

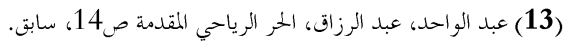

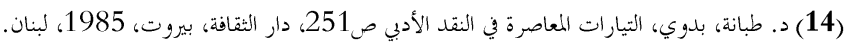

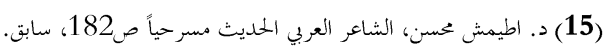

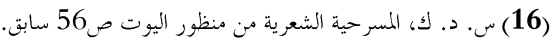

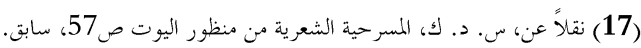

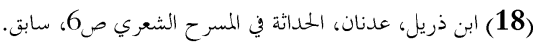
(19) أبو بنقاري، توماش، الدراما تورجيا المعاصرة، ترجمة د. كمال عيد الماند الثقافة الأجنبية، 1982، عدد33، بغداد، ص22.

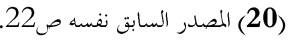

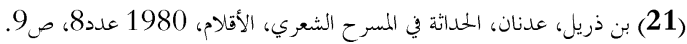

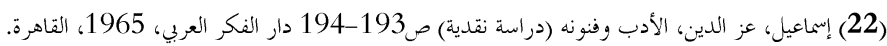

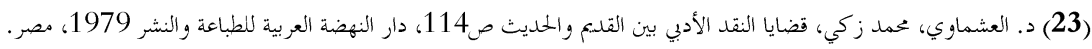


(25) د. العشري، صلاح، ثقافتنا الأصالة والمعاصرة ص200 المطإعة الثقافية، 1971، مصر.

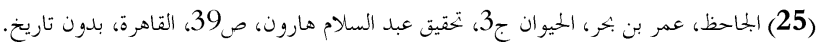

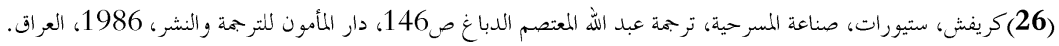

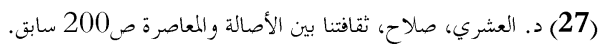

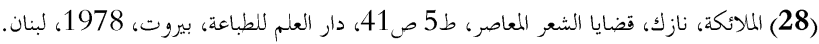

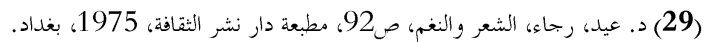

